\title{
Claudin-12 deficiency causes nerve barrier breakdown, mechanical hypersensitivity and painfulness in polyneuropathy
}

\section{Jeremy Tsung-Chieh Chen ${ }^{1 \#}$, Xiawei Hu ${ }^{1 \#}$, Kathrin Doppler ${ }^{2}$, Olga Breitkreuz-Korff ${ }^{3}$, Isabel U. C. Otto ${ }^{1}$, Joachim Schwabe ${ }^{1}$, Ann-Kristin Reinhold ${ }^{1}$, Dorothee Günzel ${ }^{4}$, Sophie Dithmer ${ }^{3}$, Mohammed K. Hankir ${ }^{5}$, Petra Fallier-Becker ${ }^{6}$, Lars Winkler ${ }^{3}$, Rosel Blasig ${ }^{3}$, Claudia Sommer ${ }^{2}$, Alexander Brack ${ }^{1}$, Ingolf E. Blasig ${ }^{3}$, Heike L. Rittner ${ }^{1 *}$}

${ }^{1}$ Department of Anesthesiology, University Hospital of Würzburg, 97080 Würzburg, Germany

${ }^{2}$ Department of Neurology, University Hospital of Würzburg, 97080 Würzburg, Germany

${ }^{3}$ Departments of Molecular Physiology and Cell Biology, Leibniz Institute of Molecular Pharmacology, 13125 Berlin, Germany

${ }^{4}$ Institute of Clinical Physiology, Charité, 12203 Berlin, Germany

${ }^{5}$ Department of Experimental Surgery, University Hospital of Würzburg, 97080 Würzburg, Germany

${ }^{6}$ Institute of Pathology and Neuropathology, University of Tübingen, 72076 Tübingen, Germany

\# These authors contributed equally to this work.

*Corresponding author: Heike Rittner, Dept. Anesthesiology and Critical Care, University Hospital of Würzburg, Oberdürrbacher Strasse 6, D-97080 Würzburg, Germany, Phone: +49931-20130254, Fax: 49-931-20130023, Email: rittner_h@ukw.de

Keywords: blood-nerve barrier; tight junction protein; Schwann cell; neuropathic pain; chronic inflammatory demyelinating neuropathy

Running title: Loss of claudin-12 results in mechanical hypersensitivity. 


\begin{abstract}
Peripheral nerves and their axons are shielded by the blood-nerve and the myelin barrier, but understanding of how these barriers impact nociception is limited. Here, we identified a regulatory axis of the tight junction protein claudin-12, sex-dependently controlling perineurial and myelin barrier integrity. In nerve biopsies, claudin-12 in Schwann cells was lost in male and postmenopausal female patients with painful but not painless polyneuropathy. Global Cldn12 gene-knockout selectively increased perineurial/myelin barrier leakage, damaged tight junction protein expression and morphology, increased proinflammatory cytokines and induced mechanical hypersensitivity in naïve and neuropathic male mice, respectively. Other barriers and neurological function remained intact. In vitro transfection studies documented claudin-12 plasma membrane localisation without interaction with other tight junction proteins or intrinsic sealing properties. Rather, claudin-12 had a regulatory tight junction protein function on the myelin barrier via the morphogen $\mathrm{SHH}$ in vivo in Cldn12-KO and after local siRNA knockdown. Fertile female mice were completely protected. Collectively, these studies reveal the critical role of claudin-12 maintaining the myelin barrier and highlight restoration of the claudin-12/SHH pathway as a potential target for painful neuropathy.
\end{abstract}




\section{Introduction}

Barriers are critical to shield delicate structures in the body. In the PNS, the blood nerve barrier (BNB) consists of the perineurium and endoneurial vessels. It is an important physiological fence which serves to maintain stable environments for axons, Schwann cells, and other endoneurial cells (Greathouse et al., 2016; Reinhold and Rittner, 2017). A second barrier in the PNS is the myelin barrier found at the paranode and the mesaxon of Schwann cells. Barriers are shaped by several main protein families: tight junction proteins, adherence junction proteins, and cytoplasmic accessory proteins (Neal and Gasque, 2016). Among the tight junction protein family, claudins [e.g. claudin-1, claudin-5, claudin-19, occludin and zona occludens (ZO-1, TPJ1)] have been identified as relevant for nerve barriers (Reinhold et al., 2018; Reinhold et al., 2019): Claudin-1 protects the perineurial barrier (Hackel et al., 2012; Sauer et al., 2014) and claudin-5, the major tight junction protein in the blood brain barrier (BBB), serves as a neuroprotector in in the endoneurial vessels (Moreau et al., 2016). Much less examined is the myelin barrier in neuropathy. Myelin tight junction proteins such as claudin-19 are responsible for sensory and motor transmissions (Guo et al., 2014). Peripheral myelin protein (PMP22) is necessary for the myelin barrier and dysregulated in inheritable neuropathies (Guo et al., 2014).

Claudin-12 is an atypical member of the claudin family because it is one of the few claudins that does not possess a PDZ binding motif. It is expressed in the intestine, urinary bladder, BBB and BNB in the nervous system (Shimizu et al., 2008; Markov et al., 2010; Amasheh et al., 2011; Reinhold and Rittner, 2017). Not very much is known about its function, except its upregulation in some types of cancer (Yang et al., 2015) and involvement in paracellular $\mathrm{Ca}^{2+}$ absorption (Fujita et al., 2008). However, its role in the BNB, myelin barrier and nociception are completely unknown.

Chronic inflammatory demyelinating polyneuropathy (CIDP) is a heterogenous (auto)immune-mediated inflammatory disease. Patients suffer from weakness, numbness and tingling and, in a subgroup, from pain (Kieseier et al., 2018). In some CIDP patients, autoantibodies against paranodal proteins are detected (Doppler et al., 2016; Dawes et al., 2018). In nerve biopsies, destruction of myelin sheaths and higher expression of inflammatory mediators such as TNF- $\alpha$ and IL-10 are found. Previous small studies have observed increased endoneurial edema at disease onset (Üceyler et al., 2016) and decreased claudin-5 and ZO-1 expression in sural nerve biopsies of CIDP patients (Kanda et al., 2004). This raises the question to the extent of which other tight junction proteins are expressed in the BNB and 
the myelin barrier are altered in CIDP patients and, if so, whether their expression is associated with painfulness.

Here, we specifically detected a loss of claudin-12 in Schwann cells in male and female postmenopausal patients with painful CIDP or non-inflammatory PNP. Using global Cldn12-

KO mice, we uncovered that Cldn12 deficiency resulted in perineurial and myelin barrier breakdown, downregulation of certain other tight junction proteins and exaggerated mechanical allodynia in naïve and neuropathic male mice. Moreover, a significant reduction of the morphogen and barrier stabilizer SHH in Cldn12-KO mice could explain the tight junction protein disruption. Together, this study clarifies the role of claudin-12 as a regulatory tight junction protein specifically in the perineurial/myelin but not BBB sealing. 


\section{Methods}

A detailed description of the methods is found in the supplementary information.

Patients and tissue donors: This study was approved by the Ethical committee of the University of Würzburg (238/17) and is registered at the German clinical trial register (DRKS00017731). Patients with a diagnosis of CIDP fulfilling the Inflammatory Neuropathy Cause and Treatment (INCAT) criteria (Hughes et al., 2008) who attended the Dept of Neurology of the University Hospital Würzburg were included in the study. Sural nerve biopsies were obtained as part of the routine workup. The resulting cohort comprised of 10/12 patients with CIDP and 10/12 control patients with non-inflammatory PNP, respectively. The diagnosis of neuropathy was based on patient history and neurological examination and included pain assessment, quantitative sensory testing and electrophysiological tests. In addition, the overall disability sum score (ODSS) was obtained. It is composed of an arm and leg disability scale with a total score ranging from 0 ("no signs of disability") to 12 ("most severe disability score") (Merkies et al., 2002). Demographics and clinical characteristics of the different cohorts are given in the Supplemental Table 1-3. Female patients were only included if postmenopausal. Sural nerve biopsies were routinely analyzed for fiber loss (low, medium, high) and type of damage (axonal, demyelinating, mixed).

Animals: Mouse experiments were performed in accordance with ARRIVE guidelines and approved by the Institutional Animal Care and Utilization Committee of the Government of Unterfranken, Germany (REG 2-264). For Cldn12-KO and WT mice, chimera with Cldn12 gene ablating deletion were first generated by transfer of the murine embryonic stem cell clone 13208A (VelociGene; http://www.velocigene.com/komp/detail/13208) into blastocysts from albino-C57BL/6J-mice $(\mathrm{B} 6(\mathrm{Cg})-\mathrm{Tyrc}-2 \mathrm{~J} / \mathrm{J})$ as provided by the Transgenic Core Facility, Max Planck Institute of Molecular Cell Biology and Genetics, Dresden/Germany. Then, the Cldn12-KO line (C57BL/6-Cldn12tm1(KOMP)Vlcg/Ph) was back-crossed ten times with C57BL/6 mice. From mating of the resulting heterozygous mice, KO and WT mice were investigated and revealed normal body-, behavior- and reproduction properties. The strain (EM:11196) is now available at EMMA strain search - Infrafrontier GmbH, Neuherberg/Germany (https://www.infrafrontier.eu/search). The animals were kept in small groups using standard cages, on 12:12 h dark-light cycle and standard diet according to the 
German animal welfare law approved by the animal ethics committee of Berlin (G0030/13, LaGeSo).

Chronic constriction injury (CCI) and nociceptive tests: We housed mice in a light and temperature-controlled room under specific pathogen free conditions. Mice had free access to food and water. Male and female Cldn12-KO and WT-C57BL/6 mice (8-10 weeks) were randomized to the treatment vs. control. Under deep anesthesia ( $2 \%$ isoflurane), we placed four loose silk ligatures (6/0) (with $1 \mathrm{~mm}$ spacing) around the $\mathrm{SN}$ at the level of the right midthigh in Cldn12-KO and WT mice (Chen et al., 2014; Reinhold et al., 2019). Ligatures were tied until they elicited a brief twitch in the respective hind limb. The muscle layer and the incision in the shaved skin layer were closed with suturing material and metal clips separately after the surgery. Mice were monitored and maintained in a controlled temperature $\left(37{ }^{\circ} \mathrm{C}\right)$ until fully recovered from anesthesia. The experimenter was blinded to the genotype.

Thermal nociceptive behavior responses were assessed by the Hargreaves method (Chen et al., 2014; Sauer et al., 2017; Reinhold et al., 2019). Static mechanical hypersensitivity was measured using von Frey filaments (Ugo Basile SRL, Italy) by using 50\% paw withdrawal threshold (PWT) method (Chen et al., 2014; Sauer et al., 2017; Reinhold et al., 2019).

Freeze-fracture electron microscopy: Approximately 4-6 $\mathrm{mm}$ of the $\mathrm{SN}$ (proximal to the sciatic trifurcation) from naïve WT and Cldn12-KO was gently freed from the surrounding connective tissue and fixed with $2.5 \%$ glutaraldehyde in PBS with $\mathrm{Ca}^{2+} / \mathrm{Mg}^{2+}$ for $2 \mathrm{~h}$ at $\mathrm{RT}$ (Wolburg et al., 2003). Quantification of TJs was conducted directly from the original images taken from 3 representative nerve preparations deriving from 4 individual animals in each group.

RNAScope method: Cryosections of $10 \mu \mathrm{m}$ thickness were cut at $-20^{\circ} \mathrm{C}$ in a cryostat (Leica Biosystems CM3050 S Research Cryostat, Leica Biosystems Nussloch GmbH, Nussloch, Germany). Tissue sections were put in precooled 4\% PFA in DEPC-treated distilled water. After $15 \mathrm{~min}$ of incubation at $4^{\circ} \mathrm{C}$, samples were dehydrated in ethanol at RT. Hydrophobic barriers were drawn around the tissue sections. Afterwards, each section was incubated with two drops of RNAscope Protease IV reagent (15 min, RT). The RNAscope assay (Advanced Cell Diagnostics, Bio-Techne, Minneapolis, USA; 320850) was performed according to manufacturer's instructions. All probes are found in the Supplemental Table 4. After blockage with $10 \%$ donkey serum in PBS, sections were immunostained with anti-claudin-1 $\mathrm{Ab}$ and secondary $\mathrm{Ab}$ to mark the perineurium. Finally, sections were mounted using 
VECTASHIELD Hardset Antifade Mounting Medium (H-1400, Vector Laboratories, Burlingame, USA).

All stainings (RNAscope, nerve permeability) were viewed using a KEYENCE BZ-9000 immunofluorescence microscope (Osaka, Japan) fitted with BZ-II analyzer software. The acquired images were analyzed using a free software package (ImageJ/Fiji). To analyze the fluorescence intensity of the immunostaining, the background was first measured in every picture. Using this corrected total cell fluorescence (CTCF) method, we calculated the integrated density, area and mean gray values of the fluorescence signal from red and green channels separately in each on region of interest (ROI).

Nerve permeability: Permeability of the BNB (perineurium): Evans blue albumin (EBA) was prepared in 5\% BSA with 1\% EB dye (Sigma-Aldrich, St. Louis, USA) in sterile distilled PBS and filtered through a $0.20 \mu \mathrm{m}$ filter (Sartorius stedim Biotech $\mathrm{GmbH}$, Germany) (Hackel et al., 2012; Reinhold et al., 2019). Dissected SNs (1 cm length, proximal to the sciatic trifurcation) from Cldn12-KO and WT were ex vivo immersed in $2 \mathrm{ml}$ of EBA for $1 \mathrm{~h}$ and then fixed with PFA (4\% paraformaldehyde) overnight. Afterwards, tissues were embedded in Tissue-Tek, cut into $10 \mu \mathrm{m}$ thick sections and mounted on microscope cover glasses with permaFluor Mountant (Thermo Scientific, Fremont, USA). The permeability of the perineurium was determined by the diffusion of EBA into the endoneurium of the SN.

Permeability of the myelin barrier: The whole SN was dissected into epiperineurium (EPN) and the desheathed SN (dSN). The dSNs were sealed with vaseline in both ends and incubated in artificial cerebrospinal fluid (as following (mM): 10 HEPES, $17.8 \mathrm{NaCl}, 2 \mathrm{NaHCO}, 4$

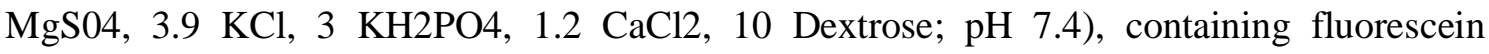
isothiocyanate-dextran (FD; $5 \mathrm{mg} / \mathrm{ml}$; MW: $70 \mathrm{kDa}$; Sigma) for $1 \mathrm{~h}$ at $37^{\circ} \mathrm{C}$. Afterwards, nerves were fixed in 4\% PFA for $5 \mathrm{~min}$ at RT, then placed on glass slides and teased into individual fibers under a dissecting microscope. We then mounted these teased fibers by VECTASHIELD Antifade Mounting Medium and covered them with microscope coverslips. The green fluorescence signal was determined.

Permeability of the BNB (endoneurial vessels): Anaesthetized mice were laid down in a supine position on a pad. The 5th intercostal space was opened and enlarged by a retractor to open the thorax. The pericardium was stripped exposing the heart anterior wall and $50 \mu \mathrm{l}$ of FD solution was injected into the left ventricle using an insulin syringe. The dye-injected mice were sacrificed by decapitation after $2 \mathrm{~min}$. SNs were dissected and embedded in Tissue-Tek. Frozen samples were cut into $12 \mu \mathrm{m}$-thick sections on a cryostat at $-20^{\circ} \mathrm{C}$. 
Without any fixation, microscope glass slides containing tissue sections were mounted and were imaged by fluorescence microscopy.

Brain microvessel isolation and $q R T-P C R$. Brain capillaries were isolated from cortices of 820 weeks-old Cldn12-KO and WT mice by homogenization in Dulbecco's modified Eagle's medium (DMEM, 4.5 g/l glucose; Life Technologies, Darmstadt, Germany) with a dounce tissue grinder (Wheaton, Millville, USA) on ice. Myelin was removed by adding dextran (60$70 \mathrm{kDa}, 16 \%$ (w/v) final concentration; Sigma-Aldrich) and centrifugation (15 min, 4,500×g, $4{ }^{\circ} \mathrm{C}$ ). The resuspended pellet was filtered (40 $\mu \mathrm{m}$ nylon mesh, Merck Millipore) and the remaining capillaries were rinsed off with DMEM and $1 \%(\mathrm{v} / \mathrm{v})$ fetal calf serum (Life Technologies) (Berndt et al., 2019).

RNA was extracted from isolated murine brain capillaries by GeneMATRIX Universal RNA Purification Kit (EURx, Gdansk, Poland). The cDNA was synthesized with the Maxima First Strand cDNA Syntheses Kit (ThermoFisher). qRT-PCR was performed with StepOne RealTime PCR system, 48/96 well (Life Technologies, Darmstadt, Germany) using the Luminaris Color HiGreen high ROX qPCR Master Mix (ThermoFisher) as described in the manual. Primer sequences with a melting temperature of around $60{ }^{\circ} \mathrm{C}$ (BioTeZ, Berlin, Germany) designed with Primer3Plus.com (Supplemental Table 5). The mRNA expression was normalized to $\beta$-actin and displayed as fold change expression calculated by the $2^{-\triangle \Delta C T}$ method as described above (Dithmer et al., 2017).

Cell culture: Cell lines from human embryonic kidney (HEK-293; (Piontek et al., 2011)) and Madin-Darby canine kidney (MDCK-II) were grown in 6-well plates until 80\% confluency and transfected using polyethylenimine (PEI; Polysciences Inc, Warrington, USA) (Cording et al., 2013). Constructs used were N-terminally fused with yellow fluorescent protein (YFP) or pmTurquoise2 (TRQ): YFP-Cldn5 (Gehne et al., 2017), YFP-Cldn12, TRQ-Cldn12 and YFP-Ocln (Bellmann et al., 2014). For each well, $10 \mu \mathrm{l}$ of PEI $(1 \mathrm{mg} / \mathrm{ml})$ was added to $250 \mu \mathrm{l}$ Opti-MEM (ThermoFisher); separately, $2 \mu \mathrm{g}$ plasmid DNA was mixed with another $250 \mu \mathrm{l}$ Opti-MEM. 5 min after incubation at RT, both solutions were combined and carefully mixed. Following $25 \mathrm{~min}$ incubation at RT, the mixture was added drop wise to each well. Transfection medium was removed after incubation overnight and cells were transferred into a $25 \mathrm{~cm}^{2}$ flask. Cells were cultured in DMEM ( $1 \mathrm{~g} / \mathrm{ml}$ glucose) containing $10 \%$ fetal calf serum and $1 \%$ penicillin/streptomycin (Thermo Fischer) at $37^{\circ} \mathrm{C}$ and $10 \% \mathrm{CO}$. For transfected cells, G418 was added to the medium (Dithmer et al., 2017). 
Live cell imaging, trans-interaction, and transepithelial electrical resistance (TER). Cells were seeded onto glass coverslips coated with poly-L-lysine (Sigma-Aldrich), washed with $\mathrm{HBSS}+/+$ (with $\mathrm{Ca}^{2+}$ and $\mathrm{Mg}^{2+}$; ThermoFisher) and imaged in HBSS+/+ using a confocal microscope (Zeiss NLO with a Plan-Neofluar 100x 1.3 Oil objective, Zeiss, Oberkochen, Germany) (Cording et al., 2013). Plasma membranes were visualized by trypan blue (0.05\%; Sigma-Aldrich) in HBSS+/+. For trans-interactions, the enrichment factor EF was detected. Half the fluorescence intensity (I) of a YFP- or TRQ-tagged protein at cell contacts between two transfected cells was divided by YFP or TRQ fluorescence at contacts between expressing and non-expressing cells (EF=Icontact/2Ino contact) (Piontek et al., 2008).

To measure the TER with a Cellzscope (nanoAnalytics, Muenster, Germany), cells were seeded onto hanging PET cell culture inserts (Merck Millipore) at a density of 80,000 cells/insert. After TER values had reached a stable plateau, the cells were transferred into a 24-well plate and washed twice with HBSS+/+ warmed to $37^{\circ} \mathrm{C}$ (Staat et al., 2015).

FRET measurements. HEK 293 cells (CRL-1573, A.T.C.C., Manassas, VA, USA; grown in Minimum Essential Medium Eagle (MEM; Sigma M0446) supplemented with 10\% (v/v) FBS (Gibco 10270106) and 1\% penicillin/streptomycin (Corning 30-002-CI) were transiently transfected with pcDNA 3.1 plasmids containing cDNA for N-terminally enhanced yellow or cyan fluorescent protein (EYFP or ECFP)-tagged murine Cldn12, human CLDN19a (NP_683763), human CLDN19b (NP_001116867) or human PMP22 (NP_000295), respectively. To this end, HEK 293 cells were seeded onto poly-lysine (Sigma P48323) coated $32 \mathrm{~mm}$ diameter cover slips (Thermo Scientific/Menzel) in six well plates (Falcon 353046). On the following day, cells were co-transfected with two plasmids encoding a YFPand a CFP-fusion protein, respectively. The total sum of plasmid DNA amounted to $4 \mu \mathrm{g} /$ well but YFP/CFP ratios varied. DNA was mixed with $10 \mu \mathrm{PEI}$ (polyethylenimine, $1 \mathrm{mg} / \mathrm{ml}$, Polysciences Europe GmbH, Eppelheim, Germany) in $500 \mu \mathrm{l}$ MEM without supplements. After 30 min incubation, the mixture was added to the cells. They were used for live cell imaging in a Zeiss LSM 780 after 24 to $48 \mathrm{~h}$. CFP and YFP fluorescence signals were excited at $458 \mathrm{~nm}$ (detection $463-507 \mathrm{~nm}$ ) and $514 \mathrm{~nm}$ (detection $518-588 \mathrm{~nm}$ ), respectively. FRET was determined as percent increase in CFP signal intensity before and after acceptor bleaching with 20 pulses of $514 \mathrm{~nm}$ laser radiation at 100\% laser power (Milatz et al., 2015).

Organ permeability. Male mice were i.v. injected with $0.5 \mathrm{~mol} / \mathrm{kg}$ b.w. Na-fluorescein (NF; Sigma-Aldrich, Munich, Germany) or $0.26 \mathrm{~mol} / \mathrm{kg}$ b.w. Evans blue (EB; Sigma-Aldrich), dissolved in saline. NF, $376 \mathrm{Da}$, served as small and EBA (due to its association to plasma 
albumin, $68 \mathrm{kDa}$ ) as large molecular weight markers. After $10 \mathrm{~min}$, mice were anesthetized i.p. using ketamine (0.18 mg/g b.w.; CP-Pharma, Burgdorf, Germany) and xylazine (0.024 mg/g b.w.; Ceva Tiergesundheit, Düsseldorf, Germany), and perfused with $25 \mathrm{ml}$ Dulbecco's phosphate-buffered saline with $\mathrm{Ca}^{2+} / \mathrm{Mg}^{2+}$ (DPBS+/+; ThermoFisher Scientific, Darmstadt, Germany) containing 6250 IU heparin (Ratiopharm, Ulm, Germany). Organs were homogenized in DPBS+/+ followed by precipitation with trichloroacetic acid (Roth, Karlsruhe, Germany; final concentration $30 \%(\mathrm{w} / \mathrm{v}))$ in the dark overnight at $4{ }^{\circ} \mathrm{C}$. After centrifugation $(19,000 \mathrm{xg}, 15 \mathrm{~min})$, fluorescence of the supernatant was measured (NF 485/520 nm; EB 620/680 nm) with a plate reader (Tecan Safire; Tecan, Männedorf, Switzerland), and referred to organ weight ( $\mu$ gdye/mgorgan; (Dithmer et al., 2017)).

siRNA treatment via perineurial injection. We use commercial siRNA to suppress local mRNA expression. Cldn5-targeting siRNA (Silencer® Pre-designed siRNA, siRNA ID: s64050, Ambion), Cldn12-targeting siRNA (Silencer ${ }^{\circledR}$ Pre-designed siRNA, siRNA ID: s82332, Ambion), Cldn19-targeting siRNA (Silencer® Pre-designed siRNA, siRNA ID: s202784, Ambion) or scrambled-siRNA-Cy3 (Mission®siRNA universal negative controls, ProducNo. SIC003, Sigma) alone were applied on the surface of the SN (2 $\mu \mathrm{g}$ of the target siRNA or scrambled-siRNA mixed with i-Fect ${ }^{\mathrm{TM}}$ (Neuromics, Edina, MN) in a ratio of 1:5 $(\mathrm{W}: \mathrm{V})$ to a final concentration of $400 \mathrm{mg} / \mathrm{L}$ ).

Fluorescence quantification ImageJ/Fiji was used to analyze our targeting fluorescence signals. To measure FD signals in teased fibers, we scanned and imaged nerve fibers from Cldn12-KO and WT mice by fluorescence microscopy at 40X magnification. Microscope and camera settings (e.g., light level, exposure, gain, etc.) were identical for all images. The number of individual fibers with positive FD penetration and the total number of individual fibers were counted and calculated. The total number of fibers was approximately 100 in 5 mice from WT and KO groups. After background subtraction in every picture, bright field images were used to guide manual selection of individual nerve fiber outlines. $20 \mu \mathrm{m}^{2}$ ROI were saved onto ROI manager. ROIs were applied on the green channel, and the selected FD signals were analyzed using the built-in plugin of ImageJ/Fiji. The mean gray values, area and integrated density of ROIs were obtained and analyzed. When the mean gray value of the ROI was bigger than 10, the related fiber was considered to be a positive FD penetration fiber. Finally, a ratio was calculated by dividing the number of positive FD penetration fibers by the total number of individual fibers. 
To analyze claudin-12-immunoreactivity (IR) signals in the SN of human and mice, coexpression regions of S100 and claudin-12 staining were selected and taken from coronal sections of the SN. S100-IR signals were used to determine location of Schwann cells, which were saved to the ROI manager. These ROIs were applied in the red channel and claudin-12IR signals in these ROIs were analyzed using the Measure built-in plugin of ImageJ/Fiji.

Statistical analyses: Statistical analysis was done using SigmaPlot or Excel software. When comparisons were more than two groups, one- or two-way ANOVA followed by the Bonferroni post-hoc test was used. For pain behavior tests, two-way RM ANOVA with Bonferroni post-hoc test was employed. The two-tailed Student's t-test was applied to examine differences between two groups. For transfected cell culture dataset, comparisons were performed using the Kruskal-Wallis-test and Dunns multiple comparison post hoc test. Differences between groups were considered significant if $\mathrm{p} \square 0.05$. All data are expressed as mean \pm SEM. 


\section{Results}

\section{Deficiency of claudin-12 in sural nerves of male or female postmenopausal patients with painful CIDP or non-inflammatory PNP}

We investigated a panel of tight junction protein typical for each barrier in sural nerves in cohorts of male or female postmenopausal CIDP patients and patients with non-inflammatory idiopathic PNP (Supplemental Table 1). Claudin-1-immunoreactivity (IR) was detected in several layers of the perineurium (Supplemental Fig S1A). Both ZO-1-IR and occludin-IR were found in all compartments of the sural nerve, e.g. perineurium, Schwann cells and endoneurial vessels (Supplemental Fig S1B, D). Claudin-5-IR was spotted in the endoneurium in endoneurial blood vessels (Supplemental Fig S1C). Claudin-19-IR was observed in the perineurium and around nerve fibers co-localizing with the Schwann cell marker S100b (Supplemental Fig S1E). Claudin-1, -19 (in S100b positive cells) and ZO-1IR were significantly reduced in PNP with severe fiber loss independently of inflammation or pain (Supplemental Fig S1F-H). No differences were found in the clinical characteristics of these groups. However, significantly more patients with CIDP were in the severe fiber loss group (Supplemental Table 2). Claudin-12-IR was predominantly located around nerve fibers of CIDP and non-inflammatory PNP patients and was co-expressed with S100b (Fig. 1). Some claudin-12-IR was observed in the perineurium. Patients with CIDP and noninflammatory PNP with pain showed a significant reduction of claudin-12-IR in sural nerve samples compared to patients without pain (Fig 1A, C) unrelated to fiber loss and inflammation (Fig 1C). No differences were found in the clinical characteristics of these groups except for sex distribution (Supplemental Table 3). In summary, claudin-12 is unique because its loss parallels pain symptoms independently of fiber loss, inflammation, demyelinating/axonal neuropathy, functional impairment and disease duration.

\section{Claudin-12 and claudin-19 loss after nerve injury}

Next, we chose to further examine the well-standardized mononeuropathy CCI in mice, characterized also by an inflammatory reaction due to the ligatures around the SN. Previous data from our and other labs revealed that CCI caused claudin-1, claudin-5, occludin and ZO1 downregulation in the SN (Moreau et al., 2016; Reinhold et al., 2018; Reinhold et al., 2019). In WT mice, claudin-12-IR was found in myelinating, MBP-positive Schwann cells and S100b-positive Schwann cells (Fig 2A). Some claudin-12-IR was observed in the perineurium. After $7 \mathrm{~d} \mathrm{CCI}$, i.e. at the time point of mechanical hypersensitivity, Cldn12 
mRNA levels in the epiperineurium (EPN), desheathed sciatic nerve (dSN) and dorsal root ganglion (DRG) were significantly lower after CCI by 60\%, 80\% and $30 \%$, respectively (Fig 2B). Similarly, claudin-12-IR was decreased by $78.2 \%$ in the $\mathrm{SN}$ of male mice (Fig 2C, D). Since claudin-19 is mainly expressed in Schwann cells (Miyamoto et al., 2005; Guo et al., 2014), we then investigated claudin-19-IR in teased nerve fibers. Claudin-19-IR was significantly decreased in the paranode of injured mice by $50 \%$ (Supplemental Fig S2A). In summary, tight junction protein expression in Schwann cells is impaired in neuropathy.

\section{Mechanical hypersensitivity in male Cldn12-KO mice}

Because of the downregulated claudin-12-IR in male or female postmenopausal patients with painful CIDP/PNP and mice with nerve injury, we generated Cldn12-KO mice to investigate the functional role of claudin-12 in the BNB and myelin barrier. We confirmed the deletion of the Cldn12 gene and protein in the PNS (Fig 2E, F) as well as several other tissues of KO mice (data not shown). To localize Cldn12 mRNA expression in the PNS, we labelled SN sections with the Cldn12 RNAscope probe and the anti-claudin-12 Ab (Fig 2G, H). Cldn12 mRNA was detected in the endoneurium and perineurium lost in KO mice. The claudin-12-IR

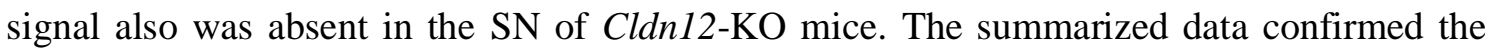
successful KO of Cldn12.

Male Cldn12-KO mice exhibited normal body weight (WT: $23.44 \pm 0.71$ g vs. Cldn12-KO: $22.13 \pm 1.26 \mathrm{~g}$ ) and normal physical appearance (Supplemental Fig S3). Gross neurological examination did not show any obvious sign of altered sensory or vestibular function in mutants. Specific evaluation of the auditory system using auditory brainstem responses, anxiety-related behavior (open field test, locomotor activity and rears), acoustic startle and pre-pulse inhibition, baseline level of immobility during habituation to the conditioning cages, contextual and cued freezing performance were also comparable between both genotypes. Only, the retinas of Cldn12-KO mice were slightly but significantly thinner than those of their WT littermates.

To determine whether the deletion of Cldn12 is involved in motor and sensory function, we performed a battery of behavioral tests in Cldn12-KO and WT mice. Motor strength test for 2paw and 4-paw handgrip as well as rotarod test showed no significant difference between KO and WT mice (Fig 3A, B). Cldn12-KO mice had significantly higher thresholds for electrical stimulation-elicited vocalization than WT mice, while thresholds for flinch and jump responses were comparable (Fig 3C). This indicates abnormal sensory processing after deletion of Cldn12. In the hot plate test, investigating supraspinal integrated thermal 
responses, no significant differences were observed (Fig 3C). However, male Cldn12-KO mice were more sensitive to mechanical stimuli (manual von Frey filaments test) at baseline levels and after CCI, while thermal sensation was unaffected (Fig 3E, F). Interestingly, no change in sensation of mechanical stimuli was observed in female Cldn12-KO, while both genotypes of fertile female mice still developed mechanical hypersensitivity after CCI (Supplemental Fig S4A). Together, these results demonstrate that Cldn12 deficiency selectively affects mechanical sensation in male mice.

\section{Leakiness of the myelin barrier and the perineurium of the BNB in male Cldn12- KO mice}

We next explored the morphological organization of the SN in Cldn12-KO (Fig 4A). Relative myelin thickness (G-ratio) and the number of undulated fibers were normal (Fig 4B, C). Undulated fibers were defined as fibers with $>4$ undulations on myelin (Yuan et al., 2018). The total number of axons was significantly lower in male Cldn12-KO (Fig 4D). Analyzing the distribution of axon and nerve fiber diameters, we found the increase in the percentage of axons with 7-9 $\mu \mathrm{m}$ diameter and a decrease in those with 3-7 $\mu \mathrm{m}$ diameter. In summary, the results could point towards a loss of small-diameter axons during embryonal development in Cldn12-KO.

To test barrier function in different organs, we used Evans blue dye associating to plasma albumin (EBA, $68 \mathrm{kDa}$ ), FITC dextran (FD, $70 \mathrm{kDa}$ ) and Na-fluorescein (368 Da). Cldn12 deficiency did not cause significant changes in barrier permeability of the brain, liver and kidney (Fig 4E). EBA immersion of the SN resulted in WT in bright red fluorescence only in the EPN of WTs. Cldn12 deficiency significantly increased the red fluorescence signal intensity within the nerve (Fig 4F) similar to perineurial leakage after CCI (Reinhold et al., 2019). No barrier breakdown was observed in endoneurial vessels after i.v. FD (Fig 4G). Using the FD immersion method for myelin barrier permeability (Guo et al., 2014), we found that the fluorescence signal significantly accumulated inside of teased nerve fibers from male Cldn12-KO mice demonstrating a leaky myelin barrier (Fig 4H). In contrast, no changes in BNB and myelin barrier permeability were noticed in fertile female Cldn12-KO mice (Supplemental Fig S4B).

In the freeze-fractured electron microscopic analysis, a significant increase in membraneassociated particle density was observed in the protoplasm-face (PF) in the $\mathrm{SN}$ of Cldn12-KO compared to WT mice (Fig 4I). In contrast, Cldn12 deficiency resulted in a significant 
reduction in the exoplasm-face (EF) associated particle density (Supplemental Table 7). Quantification of tight junction structure also revealed a significant increase in mesh length and decrease in mesh diameter in the $\mathrm{PF}$ and $\mathrm{EF}$ of male Cldn12-KO mice. In summary, deletion of Cldn12 causes an abnormal myelin barrier and perineurium permeability associated with alterations in tight junction morphology in the PNS with no effect on other barriers like the BBB.

\section{No major tight junction protein interactions nor barrier sealing properties but rather a regulatory function of claudin-12}

Since tight junction proteins form strands by inter-claudin interactions (Cording et al., 2013), we further studied whether claudin-12 interacts with other tight junction proteins in an in vitro system. Tight junction-free human embryonic kidney cells (HEK)-293 cells were transfected with yellow fluorescence protein (YFP)- or turquoise (TRQ)-tight junction protein constructs (Fig 5A-D). Claudin-12 integrated into the plasma membrane but no homophilic transinteractions were made (Fig 5B, D). Claudin-12 exhibited low grade heterophilic transinteractions with occludin (Fig 5C, D). However, no heterophilic cis-associations of claudin12 with PMP22 or claudin-19 were observed (Fig 5E). Functionally in vitro, the transepithelial resistance (TER) indicating barrier sealing remained unchanged in YFP-Cldn 12 transfected cells compared to the positive control, YFP-Cldn5 transfected cells (Fig 5F).

Since claudin-12 seemed not directly involved in barrier sealing, we next asked whether nerve injury further affects mRNA expression of known sealing tight junction proteins in the dSN or EPN of WT and Cldn12-KO mice. In naïve mice, Cldn1 mRNA levels in the EPN as well as Cldn19 mRNA levels in the dSN were significantly decreased in male Cldn12-KO mice (Fig 6A-E). $C l d n 5$ and $Z O-1$ were unaffected. In contrast, we observed a 3.5-fold upregulation of occludin. Nerve injury caused barrier breakdown and a reduction of Cldn1, Cldn5, Cldn19 and $Z O-1$ mRNA levels in $\mathrm{KO}$ and WT mice by $40-80 \%$ mice. In contrast, in isolated brain capillaries no significant differences in tight junction protein mRNA expression, e.g. Cldnl, Cldn3, Cldn5 and Ocln mRNA, were detected between male naïve WT and Cldn12-KO mice (Fig 6F). In line with barrier function and nociceptive threshold determination, no tight junction protein mRNA changes were observed in fertile female Cldn12-KO mice compared to WT mice (Supplemental Fig. S4C, D). Specifically, we did not observe a significant downregulation of Cldn19. To determine whether the proalgesic cytokine TNF- $\alpha$ contributes to mechanical hypersensitivity in $C l d n 12-\mathrm{KO}$ mice, we examined Tnf mRNA expression 
before and after CCI in the mice. We found a strikingly high expression of Tnf in Cldn12-KO mice that was similar to the expression after CCI in the WT and KO mice (Fig 6G).

Using immunostaining, we examined claudin-1-, claudin-5- and claudin-19-IR in the SN of male KO and WT mice. Claudin1-IR, which was mainly detected in the EPN, was significantly decreased in male Cldn12-KO mice (Fig 6H). No significant changes in claudin5-IR were detected in endothelial cells of endoneurial vessels of KO mice (Fig $\mathbf{6 H}$ ). Furthermore, Cldn12 deficiency resulted in a significant downregulation of claudin-19-IR in the myelin barrier compared to WT mice (Fig 6I). As observed with mRNA levels, tight junction protein-IR were comparable in fertile female Cldn12-KO and WT mice (Supplemental Fig S4C, D). In summary, Cldn12 deficiency in male mice attenuates $\mathrm{mRNA}$ /protein expression of other specific tight junction proteins sealing the perineurium and the myelin barrier, but not microvessels in the $\mathrm{SN}$ and the brain pointing towards a regulatory function in the PNS.

\section{Mechanical allodynia and myelin barrier breakdown after local suppression of Cldn12 transcription in the $\mathrm{SN}$}

We next hypothesized that the mechanical allodynia from global $\mathrm{Cldn}-12$ deficiency was a consequence of claudin-12 loss specifically in the SN. To test this hypothesis, we short-term silenced Cldn12 expression in the $\mathrm{SN}$ by siRNA. Local Cldn12-siRNA treatment downregulated Cldn12 mRNA and was sufficient to induce myelin barrier breakdown and mechanical allodynia (Fig 7A, B). Similarly, local Cldn19-siRNA application as a positive control resulted in mechanical hypersensitivity and myelin barrier leakiness with reduced Cldn19 mRNA in the dSN (Fig 7A, C). As a negative control, we applied Clnd5-siRNA, because claudin-5 was unaltered in Cldn12-KO mice. The treatment of SN with Cldn5-siRNA reduced Cldn 5 mRNA but did not cause myelin barrier collapse or mechanical allodynia (Fig 7A, D). These results demonstrate that loss of Cldn12 or Cldn19 in the SN was obligatory to the development of mechanical allodynia and myelin barrier leakiness.

\section{Impaired expression of SHH, a master barrier stabilizer, in male Cldn12-KO mice}

Because Schwann cells forming the myelin barrier were affected in Cldn12-KO, we further explored myelin associated proteins and transcription factors important for Schwann cell differentiation. The expression of Myelin Basic Protein (Mbp) mRNA, a structural protein in myelinating Schwann cells, was unaltered in the dSN of Cldn12-KO mice (Fig 8A) although these mice had a reduced number of axons (Fig 4C). In contrast, Pmp22 mRNA was 
downregulated in Cldn12-KO (Fig 8B). PMP22 is a transmembrane protein related to tight junction proteins, necessary for compact myelin formation and altered in certain forms of hereditary neuropathy (Guo et al., 2014) The Schwann cell transcription factors HMG-box 10 (Sox10) and growth response protein 2 (Krox20) play a role in nerve injury and are necessary for nerve regeneration after nerve injury (Quintes and Brinkmann, 2017). No differences of Sox10 and Krox20 mRNA were observed between the genotypes indicating no general defect in Schwann cell differentiation (Fig 8C, D).

Neuronal barriers are stabilized by the morphogen SHH (Alvarez et al., 2011). In the dSN from Cldn12-KO mice, Shh mRNA and SHH protein were significantly downregulated in naïve animals (Fig 8E, G, H). In contrast, Shh mRNA expression was normal in the cortex, liver and spleen of $\mathrm{KO}$ mice in accordance with unaltered tight junction protein mRNA expression in these tissues (Fig 8F). In the same line, Shh mRNA in fertile female mice was unaffected (Supplemental Fig S4E, F). Collectively, these results demonstrate that Cldn12 deficiency is associated with a reduction of SHH causing tight junction protein loss in the SN and myelin barrier only in the PNS, which lowers mechanical nociceptive thresholds in male animals (Fig 9). 


\section{Discussion}

In this study, we investigated the newly-discovered tight junction protein claudin-12 in peripheral nerves of patients, animals and in transfected cells. Claudin-12 was significantly lost only in male and female postmenopausal patients with painful CIDP or non-inflammatory PNP compared to the non-painful group. Male naïve and nerve-injured Cldn12-KO mice were hypersensitive to mechanical nociceptive stimuli and suffered from a breakdown of the perineurial barrier and myelin barrier in the PNS (Fig 9). Cldn12 deficiency lowered mRNA and protein expression of other tight junction proteins namely claudin-1 and -19 , and the number of myelinated axons. Loss of claudin-12 in the SN also reduced the morphogen and barrier stabilizer SHH explaining the effect on other tight junction proteins. The regulatory and barrier stabilizing role of claudin-12 was confirmed by local siRNA treatment. Together, our results suggest, for the first time, that Cldn12 expression in the PNS regulates barrier permeability and mechanical nociception via other tight junction proteins such as claudin-19, claudin-1 and SHH in male but not fertile female mice.

Low amounts of cldn-12 are expressed in microvascular cells in the brain (Ohtsuki et al., 2007; Castro Dias et al., 2019b), lung (Chen et al., 2018), intestine (Chen et al., 2018), SN (Shimizu et al., 2008) and cancer cells (Yang et al., 2015). Besides controlling $\mathrm{Ca}^{2+}$ absorption in the gastrointestinal system, the function of claudin-12 in the nervous system is unknown. It was previously postulated that claudin-12 is important for BBB formation. Since all neurological tests except for mechanical nociceptive threshold were normal in naïve Cldn12-KO mice in our study, Cldn12 seems to imply at least not to be crucial for CNS function under normal conditions. This phenotype was replicated in a recent study (Castro Dias et al., 2019a) after our study was in preprint.

Tight junction proteins are differentially expressed throughout peripheral nerves (Yang et al., 2016; Reinhold and Rittner, 2017). For example, claudin-1 is the major protein in the perineurium (Hackel et al., 2012; Sauer et al., 2014). Claudin-5 is mainly expressed in the endothelial layer of blood vessels in the SN regulating this part of the BNB (Moreau et al., 2016; Moreau et al., 2017a). Claudin19 is found in the paranode of nerve fibers (Miyamoto et al., 2005; Guo et al., 2014). Claudin-12-IR as well as Cldn12 mRNA were found in myelinating and non-myelinating Schwann cells and the perineurium. Specificity of the claudin-12 IR in Schwann cells was confirmed repeatedly in Cldn12-KO in contrast to the murine skeletal muscle in other studies (Castro Dias et al., 2019a). Cldn12 deficiency suppressed Cldn1 in the EPN and Pmp22 and Cldn19 expression in the dSN in male mice. In 
line with this, perineurium and myelin barrier were more permeable to medium-sized dyes. Cldn5 in endoneurial vessels and its barrier function were unaltered. Ocln mRNA was upregulated, but this seemed to have no functional consequence. Thus, the $C l d n 12$ deficiencyinduced leaky barrier in the SN may derive from the downregulation of claudin-1 in the perineurium and claudin-19/PMP22 in the dSN, suggesting that claudin-12 could be involved in the integrity of perineurial barrier of the BNB and myelin barrier. The presented data also imply that Cldn12 has a more prominent role in the PNS, since we observed no difference in mRNA expression of Cldn1, Cldn5 and Cldn19, or barrier function in the brain, liver and kidney of male Cldn12-KO mice. In addition, tight junction ultrastructure in the perineurium of claudin-12-free peripheral nerves was altered. This finding would explain increased tracer uptake into nerve fibers, and that the deficiency of Cldn12 causes loss of tightening and particle forming tight junction proteins, as for instance of claudin-1 (Cording et al., 2013) or claudin-19 (Miyamoto et al., 2005). Therefore, a general regulatory role of claudin-12 is assumed in peripheral nerves.

The morphogen SHH is known to regulate barrier tightness in the BBB and the BNB. In the BNB, Shh is upregulated after nerve injury as a compensatory mechanism (Moreau et al., 2016). Repressing the hedgehog/smoothened (smo) pathway via the smo receptor antagonist cyclopamine suppresses $C l d n 5$ and $O c \ln$ mRNA expression in the $\mathrm{SN}$ and elicits mechanical hypersensitivity (Moreau et al., 2016; Moreau et al., 2017a; Moreau et al., 2017b). We did not see downregulation of Cldn5 and Ocln mRNA in male Cldn12-KO mice but rather Cldn19, Cldn1 and Pmp22 mRNA. At least Pmp22 is also induced by SHH in vitro (Ingram et al., 2002). It is therefore conceivable that SHH regulates other tight junction proteins in peripheral nerves as well. In our study, Cldn12 deletion reduced Shh expression exclusively in the SN in male but not in fertile female mice. Also, Shh expression in the brain, liver and kidney of Cldn12-KO mice were unaffected. Interestingly, Shh expression can be stimulated by estrogen in estrogen receptors positive gastric cancer cells (Kameda et al., 2010). After nerve injury, estradiol improves nerve recovery, at least in part, by increasing SHH signaling and SHH-induced angiogenesis after crush injury. This is not a direct effect but rather due to a reduced expression of the SHH inhibitor hedgehog-interacting protein (HIP) in endothelial and Schwann cells (Sekiguchi et al., 2012). Thus, our data point at a role for claudin-12 in setting neuronal barrier function and imply that in its absence and with low estrogen SHH is downregulated selectively in the PNS in mice. This ultimately reduces the expression of selected tight junction proteins in the peripheral nerve forming the BNB and myelin barrier. 
Deletion of Cldn12 gene via KO or siRNA in the SN led to mechanical allodynia. Barrier breakdown could result in the dysregulated entrance of ions as well as pro-nociceptive and inflammatory mediators (e.g. IL-1 $\beta$ and TNF- $\alpha$ ) (Ji et al., 2016). Indeed, Tnf mRNA was upregulated in naïve $\mathrm{KO}$ mice. These could, for example, activate transient receptor potential vanilloid 1 (TRPV1) or transient receptor potential ankyrin 1 (TRPA1) expressed along the axonal membrane and thereby increase excitability causing hypersensitivity (Sauer and Reeh, 2009; Weller et al., 2011).

A few tight junction protein $\mathrm{KO}$ models collectively implicate critical roles for tight junction proteins in nociception in the PNS. For example, loss of junctional adhesion molecule-C (JAM-C, Jam3) in Schwann cells results in mechanical hypersensitivity (Colom et al., 2012). Tight junction protein expression in the SN is dependent on LRP1 (Hackel et al., 2012). Mice with Schwann cell-specific KO of low-density lipoprotein receptor-related protein 1 display abnormalities in axon myelination and ensheathment of axons by non-myelinating Schwann cells in Remak bundles and mechanical allodynia (Orita et al., 2013). Knockdown of Cldn11 and Cldn19 results in delayed nerve conduction velocity, abnormal behavioral responses and motor function deficiencies but nociception was not examined (Gow et al., 1999; Miyamoto et al., 2005; Maheras et al., 2018). Here, we now provide genetic evidence via full $\mathrm{KO}$ or siRNA that Cldn12 similar to Cldn19 are critical for the myelin barrier and normal mechanonociception.

Three tight junction proteins (claudin-1, -19 and ZO-1) were lowered in patients with CIDP or non-inflammatory PNP with high fiber loss, both in males and in postmenopausal females. This pattern of tight junction protein loss could simply be an associated sign of severe neuropathy and nerve destruction. Alternatively, early barrier breakdown might fuel the autoimmune attack in CIDP or the diffusion of other exogenous toxic mediators e.g. autoantibodies resulting in accelerated nerve destruction. However, the two groups did not differ in functional impairment measured by overall disability sum score (ODSS) arguing against a significant impact of clinical severity, at least. Kanda et al. described downregulated claudin-5 and ZO-1 in the biopsies of ten CIDP patients (Kanda et al., 2004). In our present larger study, tight junction protein alterations were independent of the presence of inflammation (CIDP vs. non-inflammatory PNP) and no difference in claudin-5-IR was observed. Most importantly, claudin-12 expression in Schwann cells discriminated painful from non-painful PNP. This indicates a central role of the myelin barrier in painful CIDP or non-inflammatory PNP in male and postmenopausal female patients. Future studies could 
specifically study premenopausal PNP and CIDP patients to test whether female sex hormones also protect patients against painfulness. However, these patients will be more difficult to recruit due to the epidemiology of PNPs.

The presented study has limitations including a small number of patients, only postmenopausal female patients, different etiologies of patients of non-inflammatory PNP and no healthy controls. Finally, barrier function using our functional assays would have been helpful to determine the significance of our findings.

In summary, loss of Cldn12 sex-dependently causes mechanical allodynia, operating via myelin dysfunction/degradation and SHH suppression-induced loss of selected tight junction proteins in the PNS in mice. Further, claudin-12 is decreased in CIDP or non-inflammatory PNP patients with pain. Future studies will be aimed at the exact cellular function of claudin12 in Schwann cells to understand its contribution to pain, sensory processing and barrier function. In this line, results of this study might explain the frequent side effect of pain in commonly used hedgehog/smo inhibitors for cancer treatment like sonidegib or vismodegib. Finally, pushing myelin barrier sealing via the hedgehog pathway including possible small molecules that could be used therapeutically [e.g. activation of smo with smoothened agonist (SAG) (Guo et al., 2014), purmorphamine (Chechneva et al., 2014) or oxysterols] could open new avenues in developing drug treatments for neuropathy.

\section{Acknowledgement}

We are grateful to our patients who consented to be a part of this study. We also acknowledge the invaluable assistance in animal husbandry of the ZEMM.

We thank Jianghui Hou, Washington University, St. Louis, USA, and Nina Himmerkus, Institute of Physiology, Christian-Albrechts-University of Kiel, Germany, for providing the claudin-19 Ab. We acknowledge Roland Naumann, TCF, MPI-CBG Dresden for stem cell microinjection/transfer and Mohammed Selloum, Mouse Clinical Institute, Illkirch/France for providing us with the phenotyping data of general sensory-motor function functions of Cldn12-KO and WT littermates. 


\section{Author contributions}

JTC and HLR were responsible for the study concept and design. JTC, XH and IUO conducted the PNS barrier analyses and pain behavior experiments. IEB, RB, OBK generated and analyzed the claudin-12-KO. DG, LW and SD performed the in vitro experiments. PFB accomplished the tight junction morphology experiments. CS and KD conducted the clinical study. JS, AKR and XH analyzed the patients' samples. CS, AB and IEB provided critical revision and important intellectual content. HLR, AKR and $\mathrm{XH}$ obtained funding for the study. JTC, MKH and HLR drafted and edited the article.

\section{Competing interests}

HLR and CS received funding for drug studies regarding complex regional pain syndrome by Grünenthal.

\section{Conflict of interest:}

The authors have declared that no conflict of interest exists.

\section{The paper explained}

\section{Problem}

Tight junction proteins seal the blood-nerve and blood myelin barrier. However, the role the tight junction proteins claudin-12 expressed in peripheral nerves is inexplicable and lacks clinical evidence and basic scientific mechanisms.

\section{Results}

We serendipitously found that in male or female postmenopausal patients with chronic inflammatory demyelinating polyneuropathy and non-inflammatory polyneuropathy, pain was specifically associated with reduced claudin-12 immunoreactivity in Schwann cells of the sural nerve. This led us to hypothesis that neuropathic pain arises from peripheral myelin barrier integrity breakdown due to the absence of claudin-12. We next created a germline knockout mouse line demonstrating that global deficiency in claudin-12 leads to mechanical hypersensitivity, perineurial and myelin barrier breakdown only in male mice. Furthermore, selected other tight junction proteins and the barrier-stabilizing molecule sonic hedgehog in the PNS were downregulated. Other barriers including the blood brain barrier and female 
mice were unaffected, suggesting a role of claudin-12 in maintaining peripheral myelin barrier integrity.

\section{Impact}

Our work indicates that claudin-12 is a regulatory tight junction protein for the myelin barrier in Schwann cells controlling mechanical nociceptive pain sensation sex-dependently in patients and mice. This study further implies tha claudin-12 and the SHH pathway could be an attractive target for novel neuropathic pain therapies protecting myelin barriers.

\section{Funding}

This study was supported by the Else-Kröner-Fresenius Foundation and the German Research Foundation (Ri817/13-1) (HLR). XH received founding from the China Scholarship Council. AKR was supported by the Interdisciplinary Center of Clinical Research (IZKF). 


\section{References}

Alvarez JI, Dodelet-Devillers A, Kebir H, Ifergan I, Fabre PJ, Terouz S, et al. The Hedgehog pathway promotes blood-brain barrier integrity and CNS immune quiescence. Science 2011; 334(6063): 1727-31.

Amasheh S, Fromm M, Gunzel D. Claudins of intestine and nephron - a correlation of molecular tight junction structure and barrier function. Acta Physiol (Oxf) 2011; 201(1): 13340.

Bellmann C, Schreivogel S, Gunther R, Dabrowski S, Schumann M, Wolburg H, et al. Highly conserved cysteines are involved in the oligomerization of occludin-redox dependency of the second extracellular loop. Antioxid Redox Signal 2014; 20(6): 855-67.

Berndt P, Winkler L, Cording J, Breitkreuz-Korff O, Rex A, Dithmer S, et al. Tight junction proteins at the blood-brain barrier: far more than claudin-5. Cell Mol Life Sci 2019; 76(10): 1987-2002.

Castro Dias M, Coisne C, Baden P, Enzmann G, Garrett L, Becker L, et al. Claudin-12 is not required for blood-brain barrier tight junction function. Fluids Barriers CNS 2019a; 16(1): 30.

Castro Dias M, Coisne C, Lazarevic I, Baden P, Hata M, Iwamoto N, et al. Claudin-3deficient C57BL/6J mice display intact brain barriers. Sci Rep 2019b; 9(1): 203.

Chechneva OV, Mayrhofer F, Daugherty DJ, Krishnamurty RG, Bannerman P, Pleasure DE, et al. A Smoothened receptor agonist is neuroprotective and promotes regeneration after ischemic brain injury. Cell Death Dis 2014; 5: e1481.

Chen H, Lu R, Zhang YG, Sun J. Vitamin D Receptor Deletion Leads to the Destruction of Tight and Adherens Junctions in Lungs. Tissue Barriers 2018; 6(4): 1-13.

Chen JT, Guo D, Campanelli D, Frattini F, Mayer F, Zhou L, et al. Presynaptic GABAergic inhibition regulated by BDNF contributes to neuropathic pain induction. Nat Commun 2014; 5: 5331.

Colom B, Poitelon Y, Huang W, Woodfin A, Averill S, Del Carro U, et al. Schwann cellspecific JAM-C-deficient mice reveal novel expression and functions for JAM-C in peripheral nerves. FASEB J 2012; 26(3): 1064-76.

Cording J, Berg J, Kading N, Bellmann C, Tscheik C, Westphal JK, et al. In tight junctions, claudins regulate the interactions between occludin, tricellulin and marvelD3, which, inversely, modulate claudin oligomerization. J Cell Sci 2013; 126(Pt 2): 554-64.

Dawes JM, Weir GA, Middleton SJ, Patel R, Chisholm KI, Pettingill P, et al. Immune or Genetic-Mediated Disruption of CASPR2 Causes Pain Hypersensitivity Due to Enhanced Primary Afferent Excitability. Neuron 2018; 97(4): 806-22 e10.

Dithmer S, Staat C, Muller C, Ku MC, Pohlmann A, Niendorf $\mathrm{T}$, et al. Claudin peptidomimetics modulate tissue barriers for enhanced drug delivery. Ann N Y Acad Sci 2017; 1397(1): 169-84.

Doppler K, Appeltshauser L, Villmann C, Martin C, Peles E, Kramer HH, et al. Autoantibodies to contactin-associated protein 1 (Caspr) in two patients with painful inflammatory neuropathy. Brain 2016; 139(Pt 10): 2617-30.

Fujita H, Sugimoto K, Inatomi S, Maeda T, Osanai M, Uchiyama Y, et al. Tight junction proteins claudin-2 and -12 are critical for vitamin D-dependent $\mathrm{Ca} 2+$ absorption between enterocytes. Molecular biology of the cell 2008; 19(5): 1912-21.

Gehne N, Lamik A, Lehmann M, Haseloff RF, Andjelkovic AV, Blasig IE. Cross-over endocytosis of claudins is mediated by interactions via their extracellular loops. PLoS One 2017; 12(8): e0182106. 
Gow A, Southwood CM, Li JS, Pariali M, Riordan GP, Brodie SE, et al. CNS myelin and sertoli cell tight junction strands are absent in Osp/claudin-11 null mice. Cell 1999; 99(6): 649-59.

Greathouse KM, Palladino SP, Dong C, Helton ES, Ubogu EE. Modeling leukocyte trafficking at the human blood-nerve barrier in vitro and in vivo geared towards targeted molecular therapies for peripheral neuroinflammation. J Neuroinflammation 2016; 13: 3.

Guo J, Wang L, Zhang Y, Wu J, Arpag S, Hu B, et al. Abnormal junctions and permeability of myelin in PMP22-deficient nerves. Ann Neurol 2014; 75(2): 255-65.

Hackel D, Krug SM, Sauer RS, Mousa SA, Bocker A, Pflucke D, et al. Transient opening of the perineurial barrier for analgesic drug delivery. Proc Natl Acad Sci U S A 2012; 109(29): E2018-27.

Hughes RA, Donofrio P, Bril V, Dalakas MC, Deng C, Hanna K, et al. Intravenous immune globulin (10\% caprylate-chromatography purified) for the treatment of chronic inflammatory demyelinating polyradiculoneuropathy (ICE study): a randomised placebo-controlled trial. Lancet Neurol 2008; 7(2): 136-44.

Ingram WJ, Wicking CA, Grimmond SM, Forrest AR, Wainwright BJ. Novel genes regulated by Sonic Hedgehog in pluripotent mesenchymal cells. Oncogene 2002; 21(53): 8196-205.

Ji RR, Chamessian A, Zhang YQ. Pain regulation by non-neuronal cells and inflammation. Science 2016; 354(6312): 572-7.

Kameda C, Nakamura M, Tanaka H, Yamasaki A, Kubo M, Tanaka M, et al. Oestrogen receptor-alpha contributes to the regulation of the hedgehog signalling pathway in ERalphapositive gastric cancer. Br J Cancer 2010; 102(4): 738-47.

Kanda T, Numata Y, Mizusawa H. Chronic inflammatory demyelinating polyneuropathy: decreased claudin-5 and relocated ZO-1. J Neurol Neurosurg Psychiatry 2004; 75(5): 765-9.

Kieseier BC, Mathey EK, Sommer C, Hartung HP. Immune-mediated neuropathies. Nat Rev Dis Primers 2018; 4(1): 31.

Maheras KJ, Peppi M, Ghoddoussi F, Galloway MP, Perrine SA, Gow A. Absence of Claudin 11 in CNS Myelin Perturbs Behavior and Neurotransmitter Levels in Mice. Sci Rep 2018; 8(1): 3798.

Markov AG, Veshnyakova A, Fromm M, Amasheh M, Amasheh S. Segmental expression of claudin proteins correlates with tight junction barrier properties in rat intestine. J Comp Physiol B 2010; 180(4): 591-8.

Merkies IS, Schmitz PI, van der Meche FG, Samijn JP, van Doorn PA, Inflammatory Neuropathy $\mathrm{C}$, et al. Clinimetric evaluation of a new overall disability scale in immune mediated polyneuropathies. J Neurol Neurosurg Psychiatry 2002; 72(5): 596-601.

Milatz S, Piontek J, Schulzke JD, Blasig IE, Fromm M, Gunzel D. Probing the cisarrangement of prototype tight junction proteins claudin-1 and claudin-3. Biochem J 2015; 468(3): 449-58.

Miyamoto T, Morita K, Takemoto D, Takeuchi K, Kitano Y, Miyakawa T, et al. Tight junctions in Schwann cells of peripheral myelinated axons: a lesson from claudin-19-deficient mice. The Journal of cell biology 2005; 169(3): 527-38.

Moreau N, Dieb W, Mauborgne A, Bourgoin S, Villanueva L, Pohl M, et al. Hedgehog Pathway-Mediated Vascular Alterations Following Trigeminal Nerve Injury. J Dent Res 2017a; 96(4): 450-7.

Moreau N, Mauborgne A, Bourgoin S, Couraud PO, Romero IA, Weksler BB, et al. Early alterations of Hedgehog signaling pathway in vascular endothelial cells after peripheral nerve 
injury elicit blood-nerve barrier disruption, nerve inflammation, and neuropathic pain development. Pain 2016; 157(4): 827-39.

Moreau N, Mauborgne A, Couraud PO, Romero IA, Weksler BB, Villanueva L, et al. Could an endoneurial endothelial crosstalk between Wnt/beta-catenin and Sonic Hedgehog pathways underlie the early disruption of the infra-orbital blood-nerve barrier following chronic constriction injury? Mol Pain 2017b; 13: 1744806917727625.

Neal JW, Gasque P. The role of primary infection of Schwann cells in the aetiology of infective inflammatory neuropathies. J Infect 2016; 73(5): 402-18.

Ohtsuki S, Sato S, Yamaguchi H, Kamoi M, Asashima T, Terasaki T. Exogenous expression of claudin-5 induces barrier properties in cultured rat brain capillary endothelial cells. J Cell Physiol 2007; 210(1): 81-6.

Orita S, Henry K, Mantuano E, Yamauchi K, De Corato A, Ishikawa T, et al. Schwann cell LRP1 regulates remak bundle ultrastructure and axonal interactions to prevent neuropathic pain. J Neurosci 2013; 33(13): 5590-602.

Piontek J, Fritzsche S, Cording J, Richter S, Hartwig J, Walter M, et al. Elucidating the principles of the molecular organization of heteropolymeric tight junction strands. Cell Mol Life Sci 2011; 68(23): 3903-18.

Piontek J, Winkler L, Wolburg H, Muller SL, Zuleger N, Piehl C, et al. Formation of tight junction: determinants of homophilic interaction between classic claudins. FASEB J 2008; 22(1): 146-58.

Quintes S, Brinkmann BG. Transcriptional inhibition in Schwann cell development and nerve regeneration. Neural Regen Res 2017; 12(8): 1241-6.

Reinhold AK, Rittner HL. Barrier function in the peripheral and central nervous system-a review. Pflugers Archiv : European journal of physiology 2017; 469(1): 123-34.

Reinhold AK, Schwabe J, Lux TJ, Salvador E, Rittner HL. Quantitative and Microstructural Changes of the Blood-Nerve Barrier in Peripheral Neuropathy. Front Neurosci 2018; 12: 936.

Reinhold AK, Yang S, Chen JT, Hu L, Sauer RS, Krug SM, et al. Tissue plasminogen activator and neuropathy open the blood-nerve barrier with upregulation of microRNA-1555p in male rats. Biochim Biophys Acta Mol Basis Dis 2019; 1865(6): 1160-9.

Sauer RS, Kirchner J, Yang S, Hu L, Leinders M, Sommer C, et al. Blood-spinal cord barrier breakdown and pericyte deficiency in peripheral neuropathy. Ann N Y Acad Sci 2017; 1405(1): 71-88.

Sauer RS, Krug SM, Hackel D, Staat C, Konasin N, Yang S, et al. Safety, efficacy, and molecular mechanism of claudin-1-specific peptides to enhance blood-nerve-barrier permeability. J Control Release 2014; 185: 88-98.

Sauer SK, Reeh PW. Inflammation and hypersensitivity in the context of the sensory functions of axonal membranes: what are the molecular mechanisms? Dig Dis 2009; 27 Suppl 1: $11-5$.

Sekiguchi H, Ii M, Jujo K, Renault MA, Thorne T, Clarke T, et al. Estradiol triggers sonichedgehog-induced angiogenesis during peripheral nerve regeneration by downregulating hedgehog-interacting protein. Lab Invest 2012; 92(4): 532-42.

Shimizu F, Sano Y, Maeda T, Abe MA, Nakayama H, Takahashi R, et al. Peripheral nerve pericytes originating from the blood-nerve barrier expresses tight junctional molecules and transporters as barrier-forming cells. J Cell Physiol 2008; 217(2): 388-99.

Staat C, Coisne C, Dabrowski S, Stamatovic SM, Andjelkovic AV, Wolburg H, et al. Mode of action of claudin peptidomimetics in the transient opening of cellular tight junction barriers. Biomaterials 2015; 54: 9-20. 
Üceyler N, Necula G, Wagemann E, Toyka KV, Sommer C. Endoneurial edema in sural nerve may indicate recent onset inflammatory neuropathy. Muscle Nerve 2016; 53(5): 70510.

Weller K, Reeh PW, Sauer SK. TRPV1, TRPA1, and CB1 in the isolated vagus nerve--axonal chemosensitivity and control of neuropeptide release. Neuropeptides 2011; 45(6): 391-400.

Wolburg H, Liebner S, Lippoldt A. Freeze-fracture studies of cerebral endothelial tight junctions. Methods Mol Med 2003; 89: 51-66.

Yang S, Krug SM, Heitmann J, Hu L, Reinhold AK, Sauer S, et al. Analgesic drug delivery via recombinant tissue plasminogen activator and microRNA-183-triggered opening of the blood-nerve barrier. Biomaterials 2016; 82: 20-33.

Yang Y, Cheon S, Jung MK, Song SB, Kim D, Kim HJ, et al. Interleukin-18 enhances breast cancer cell migration via down-regulation of claudin-12 and induction of the p38 MAPK pathway. Biochem Biophys Res Commun 2015; 459(3): 379-86.

Yuan X, Klein D, Kerscher S, West BL, Weis J, Katona I, et al. Macrophage Depletion Ameliorates Peripheral Neuropathy in Aging Mice. J Neurosci 2018; 38(19): 4610-20. 


\section{Figure legends}

Figure 1 Reduced claudin-12-immunoreactivtiy (IR) in Schwann cells in sural nerves in a subgroup of patients with painful chronic inflammatory demyelinating polyneuropathy (CIDP) or non-inflammatory polyneuropathy (PNP). (A-C) Sections from sural nerves of 23 patients with either non-inflammatory PNP or CIDP were immunolabeled. Patients were grouped according to pain symptoms (red) and extend of fiber loss (blue) and presence/absence of inflammation (grey) (patients characteristics': Supplemental Table 2 and 3). Representative immunostainings for claudin-12 (red) costained with the Schwann cell marker S100b (green) are displayed comparing a patient with (A) and without (B) pain and moderate fiber loss. Higher magnification merged views (white square) are shown in the lower row (scale bar upper row $=50 \mu \mathrm{m}$, scale bar lower low $=25$ $\mu \mathrm{m})$. (C) Claudin-12-IR within S100b+ was quantified according to patients' subgroups with pain symptoms, extend of fiber loss and inflammation. PNP controls included idiopathic, vasculitic, hereditary and alcoholic PNP. The number of patients in each group are found below the dot plots. ${ }^{*} \mathrm{p}<0.05$, two-sided Student's t-test. Data are shown as mean \pm SEM.

Figure 2 Claudin-12 loss in the sciatic nerve after nerve injury and generation of Cldn12-KO mice. WT mice underwent chronic constriction injury (CCI) for $7 \mathrm{~d}$. (A) Triple labeling was performed with claudin-12 (red) and myelin basic protein (MBP; green) and S100b (blue) for Schwann cells in naïve mice [representative example; scale bar: $20 \mu \mathrm{m}$ ]. (B) Cldn12 mRNA expression in the desheathed sciatic nerve (dSN), epiperineurium (EPN) and dorsal root ganglion (DRG) was analyzed in naïve and CCI mice. (\#\#p $<0.01$, EPN, DRG vs. dSN WT; **p $<0.01, * * * p<0.001$, naïve versus CCI WT, two-way ANOVA followed by Bonferroni's post hoc test; $\mathrm{n}=6)(\mathbf{C}-\mathrm{D})$ Double-label immunostaining was performed showing coexpression of claudin-12 (red) and S100b (green) in the sciatic nerve (SN) of untreated naive and CCI mice [representative example; scale bar image overview: $25 \mu \mathrm{m}$, scale bar magnified image (white square): $10 \mu \mathrm{m}$ ] and quantified $(* * \mathrm{p}<0.01$, one-tailed Student's t-test; $\mathrm{n}=4-5$ ). (E, F) Cldn12-KO mice were generated as described in the methods. Representative examples of Cldn12 mRNA and protein expression in dSN, EPN and DRG tissues in Cldn12-KO and WT are displayed. Uncropped blots are provided in Supplemental Fig S5A, B. (G) Characteristic images of RNAscope ${ }^{\circledR}$ fluorescent assay for Cldn12 mRNA (red) are presented which were co-stained with immunostaining for claudin-1 (green) and DAPI (blue) in the SN of WT and Cldn12-KO mice (scale bar: $50 \mu \mathrm{m}$ ). P: perineurium, E: endoneurium. (H) Immunofluorescence imaging of sectioned SN from WT and Cldn12-KO 
mice stained with claudin-12 (red) and S100b (green) antibody respectively (scale bar: 20 $\mu \mathrm{m})$. Data are shown as mean \pm SEM.

Figure 3 Mechanical hypersensitivity in male Cldn12-KO mice. (A-D) Behavioral tests were performed with naïve male Cldn12-KO mice in comparison with naïve male WT mice. (A) Slip thresholds of two and four paws were analyzed by the grip strength test. (B) The latency to fall of the Rota rod was tested in both genotypes. (C) Vocalization, flinch and jump thresholds to foot shock stimuli were obtained and averaged. (D) Nociceptive response latencies to a hot-plate surface were measured (all above $* \mathrm{p}<0.05$, unpaired two-sided Student's t-test, $\mathrm{n}=9$ ). ( $\mathbf{E}, \mathbf{F})$ Mice underwent CCI surgery. Nociceptive thresholds were obtained before and every day after CCI: Thermal hypersensitivity was detected in the Hargreaves test $(\mathbf{E})$ and static mechanical hypersensitivity by Frey filaments test $(\mathbf{F})(\mathrm{n}=10$, IL: ipsilateral, CL: contralateral, two-way RM-ANOVA, Bonferroni's post hoc test. ***p <

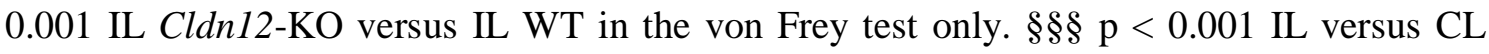
Cldn12-KO, \#\#\# p < 0.001 IL versus CL WT). Data are shown as mean \pm SEM.

Figure 4 Cldn12 deficiency results in selective nerve barrier breakdown and axonal loss.

(A) Representative images of transverse semithin sections of the sciatic nerve from WT and Cldn12-KO mice including higher magnification (white square) are displayed. (B) The ratio of inner axonal diameter to total outer diameter of nerve fibers (g-ratio) in relation to the fiber diameter and $(\mathbf{C})$ the number of undulated fibers. (D) The number of myelinated axons in the $\mathrm{SN}$ and distribution of the diameters of myelinated axons were quantified $(* \mathrm{p}<0.05$, onetailed Student's t-test; ${ }^{*} \mathrm{p}<0.001$, Pearson's Chi-squared test; $\mathrm{n}=4$, scale bar: $\left.50 \mu \mathrm{m}\right)$. (E) Uptake of Na-fluorescein $(0.5 \mathrm{~mol} / \mathrm{kg}$, i.v. $)$ and Evans blue dye associated to serum or plasma albumin (EBA, $0.26 \mathrm{~mol} / \mathrm{kg}$, i.v.; each $10 \mathrm{~min}$ after injection) were measured in brain, liver and kidney from WT and Cldn12-KO mice (two-way ANOVA, followed by Bonferroni post hoc test, $\mathrm{n}=3)$. ( F-H) Permeabilities of the blood nerve barrier (BNB) and myelin barrier in the SN were evaluated. (F) Examples of EBA penetration in into SN (left) and quantification (right) of fluorescence signals as measurement of the perineurial barrier of the BNB are shown (scale bar: $50 \mu \mathrm{m}$ ). (G) Diffusion of FD (left) and FD fluorescence was quantified in endoneurial microvessels 2 min after i.v. FD injection (right) as part of the BNB (**p $<0.01$, two-tailed Student's t-test, n $(\mathrm{EBA})=4, \mathrm{n}(\mathrm{FD})=5$, scale bar: $50 \mu \mathrm{m})$. (H) Myelin barrier permeability was assessed by FD penetration into teased sciatic nerve fibers (left). The number of FD positive and negative fibers in the SN (right) was investigated (\#\#\# $p<0.001$, Pearson's Chi-squared test with Yates' continuity correction, $\mathrm{n}=105-110$ fibers from 
5 mice/group, scale bar: $20 \mu \mathrm{m}$ ). (I) Freeze-fracture electron microscopy of the tight junction strand network was performed in the SN from WT and KO mice. Tight junction particles associated to the strands of the protoplasmic face (PF) and exoplasmic face (EF) and mesh characteristics were quantified (Supplemental Table 7, scale bars: $250 \mathrm{~nm}$ and $100 \mathrm{~nm}$ as indicated). $\mathrm{n}=3$ images from 4 mice/group.

Figure 5 No major heterophilic or homophilic cis/trans interaction, nor an increase in transcellular electrical resistance (TER) of claudin-12. Tight junction-free HEK-293 cells transfected with yellow fluorescence protein (YFP)- or turquoise fluorescence protein (TRQ)tagged claudin and occludin are shown, respectively. (A) Yellow arrows indicate claudin-5 enriched in tight junction between transfected cells (red color: trypane blue as membrane marker; live-cell imaging, scale bar: $25 \mu \mathrm{m}$ ). (B) TRQ-Cldn12 distribution was analyzed in cell contacts. Blue arrowheads indicate partial enrichment in tight junctions. (C) Representative images with double transfection are displayed. Green arrows depict contacts between claudin-12 and occludin in the tight junction. Open blue arrows show membrane location of claudin-12 in contacts with non-transfected cells. Yellow arrows indicate contacts between occludin expressing cells. (D) The enrichment factor (EF) between TRQ-Cldn12 in the tight junctions $(\mathrm{EF} \sim 1)$, positive control YFP-Cldn5 (EF>1, homophilic trans-interaction between neighboring membranes; $\mathrm{n}=5$ ) and TRQ-Cldn12/YFP-Ocln/YFP-Cldn5 heterophilic trans-interactions were quantified $(* \mathrm{p}<0.05$, compared to claudin-12, Kruskal-Wallis-test and Dunn's multiple comparison post hoc test, $\mathrm{n}>15$ ). (E) Förster resonance energy transfer (FRET) analysis efficiencies measured cis-interaction between claudin-12 and PMP22 ( $\mathrm{n}=$ 25), claudin-19b and PMP22 ( $\mathrm{n}=24)$, claudin-12 and claudin-19a ( $=17)$ or claudin-19b ( $=15$ ) (single sample student's t-test with post hoc Bonferroni-Holm analysis). FRET analysis efficiency between claudin-19a and claudin-19b is displayed as positive control $(n=6$, single sample student's t-test with post hoc Bonferroni-Holm analysis; *p < 0.05). (F) Measurement of TER in MDCK-II cells transfected with YFP-Cldn5 (positive control), YFP (vector control), and YFP-Cldn12 (*p $<0.05$, one-tailed Student's t-test, $\mathrm{n}=3$ ). Data are shown as mean \pm SEM.

Figure 6 Reduction of $C l d n 1$ and $C l d n 19$ mRNA and protein in the sciatic nerve (SN) in Cldn12-KO mice. The mRNA expression of Cldn1 in the epiperineurium (EPN) (A), Cldn5 (B) Cldn19 (C), Ocln (D) and ZO-1 (Tjp1) (E) in the desheathed sciatic nerve (dSN) was quantified in WT or Cldn12-KO mice before and $7 \mathrm{~d}$ after CCI $(\# \mathrm{p}<0.05$, \#\# $<$ 0.001, naïve Cldn12-KO versus naive WT. ${ }^{*} \mathrm{p}<0.05$, ***p $<0.001$, CCI versus corresponding 
cohorts from naive WT, $\mathrm{n}=5-6)$. (F) Cldn1, Cldn3, Cldn5, Cldn12 and Ocln mRNA expression was analyzed in isolated brain capillaries of Cldn12-KO and WT mice $(\mathrm{n}=4-5$, non-detectable, n.d.). (G) Tnf mRNA expression in the desheathed sciatic nerve (dSN) from WT or Cldn12-KO mice before and $7 \mathrm{~d}$ after CCI. (\#p $<0.05$, naïve Cldn12-KO versus naive WT. $* * * p<0.001$, CCI versus corresponding cohorts from naive WT, $\mathrm{n}=6-7)(\mathbf{H})$ Examples of immunostainings for claudin-1 (red) and claudin-5 (green) in the SN are displayed and quantified in naïve Cldn12-KO and WT (bottom, $\mathrm{n}=4$, scale bar: $50 \mu \mathrm{m}$ ). (I) Representative images of claudin-19-IR and quantification (bottom) in paranode of teased nerve fibers are shown. Nodal regions were identified with a anti pan-sodium channel Ab (pan-Nav). All above two-tailed Student's t-test. **p $<0.01$, naïve KO nerve fibers versus nerve fibers from naive WT, $\mathrm{n}=101-104$ nerve fibers from four mice per group. Data are presented as mean \pm SEM. Scale bar: $20 \mu \mathrm{m}$.

Figure 7 Mechanical allodynia and myelin barrier breakdown after Cldn12 suppression. (A-D) Mice were treated with a single perisciatic injection of scrambled (scr), Cldn12-, Cldn19- and Cldn5-siRNA. (A) Desheathed sciatic nerves (dSN) were incubated with FICTdextran (FD) ex vivo after respective in vivo siRNA treatment. Representative images of teased fibers are displayed (scale bar: $50 \mu \mathrm{m}$ ). Ratios of FD positive fibers from Cldn12- (B), Cldn19- (C), Cldn5- (D) or scrambled-siRNA treated sciatic nerve (left panel) were quantified. Mechanical nociceptive thresholds (middle panel, baseline, BL, and after siRNA application) and mRNA expression of Cldn12, Cldn19 and Cldn5 in the SN (right panels) were analyzed following the siRNA injection. $(* \mathrm{p}<0.05$, **p $<0.01$, ***p $<0.001, \mathrm{Cldn}$ siRNA versus scrambled-siRNA, two-tailed Student's t-test, $n=5-6$; \#\#\# $<0.001$, Pearson's Chi-squared test with Yates' continuity correction, $\mathrm{n}=78-118$ fibers from 4-5 mice per groups). Data are presented as mean \pm SEM.

Figure 8 Cldn12 deficiency results in downregulation of Shh expression in the SN, but not in the brain cortex, liver and kidney. (A) The mRNA expression of myelin basic protein $(M b p),(\mathbf{B})$ peripheral myelin protein 22 (Pmp22) and the two transcription factors $(\mathbf{C})$ Sox10, (D) Krox20 and (E) Shh were measured in the dSN from WT and Cldn12-KO mice. The mRNA expression was always expressed as fold change to naïve WT mice. (F) The Shh mRNA was quantified in the brain cortex, kidney and liver from WT and KO mice. (G) Representative images of Western blot analysis of SHH protein expression in the dSN from WT and KO mice. Bands were analyzed by densitometry (intensity density value, IDV). Uncut blots are found in Supplemental Fig S5. $* \mathrm{p}<0.05, * * \mathrm{p}<0.01$, naïve Cldn12-KO 
versus naïve WT, all two-tailed Student's t-test, PCR $n=6$, Western blot $n=8$ ). Data are presented as mean $\pm \mathrm{SEM}$.

Figure 9 Role of claudin-12 on nerve barriers sealing and pain. Drawing depicts the possible cellular and molecular events in the presence (left) and absence of claudin-12 (right). Reduced claudin-12 or KO increases the permeability of the perineurial and the myelin barrier in male mice. Claudin-12 $\mathrm{KO}$ is accompanied by reduced levels of the morphogen $\mathrm{SHH}$ thereby destabilizing barriers via reduced expression tight junction protein networks including claudin-1 and claudin-19. 

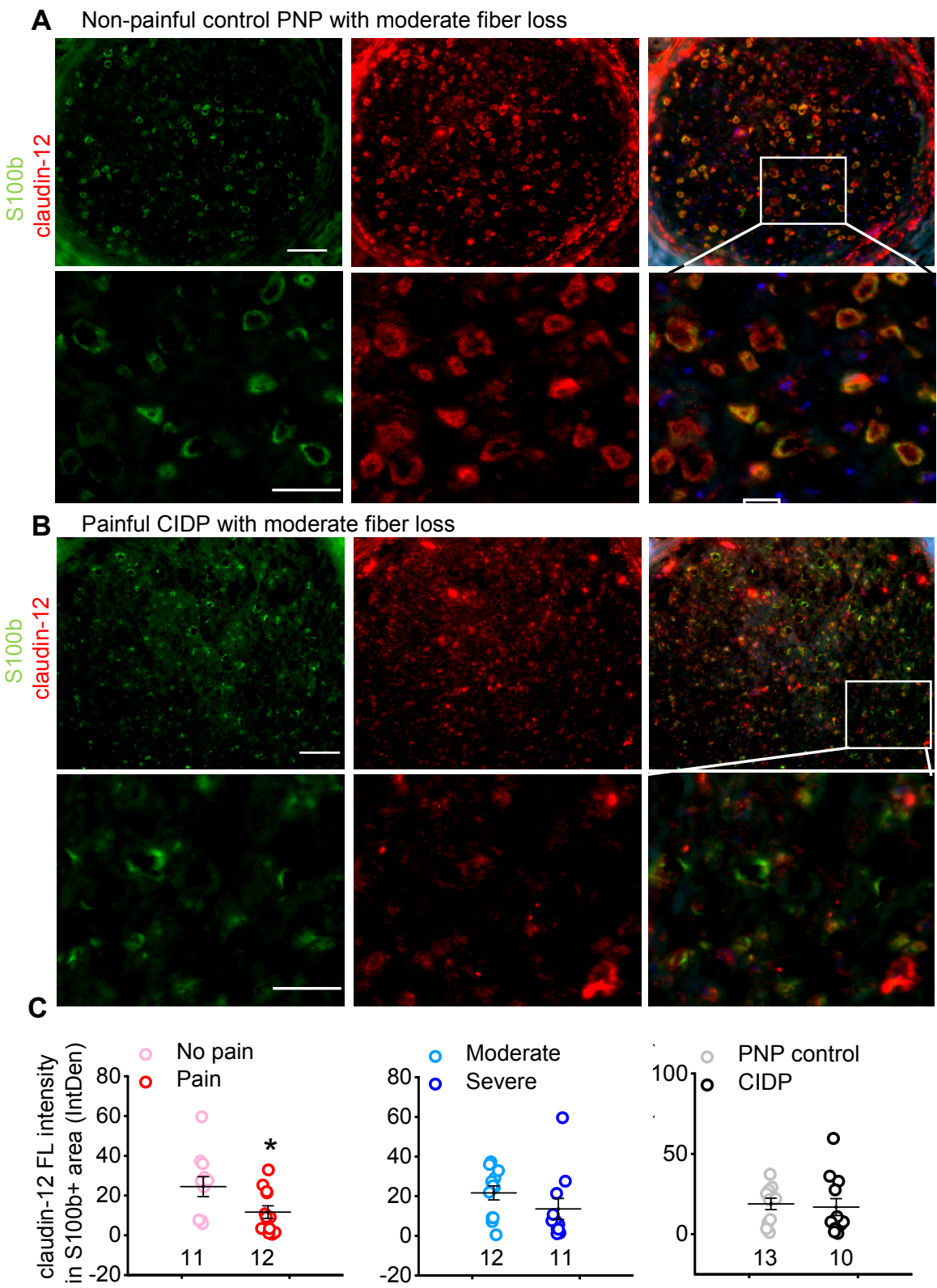

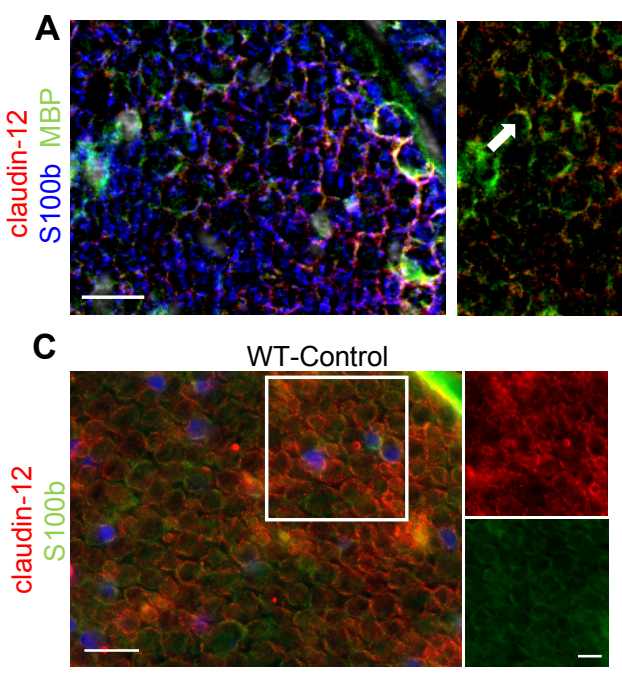

E
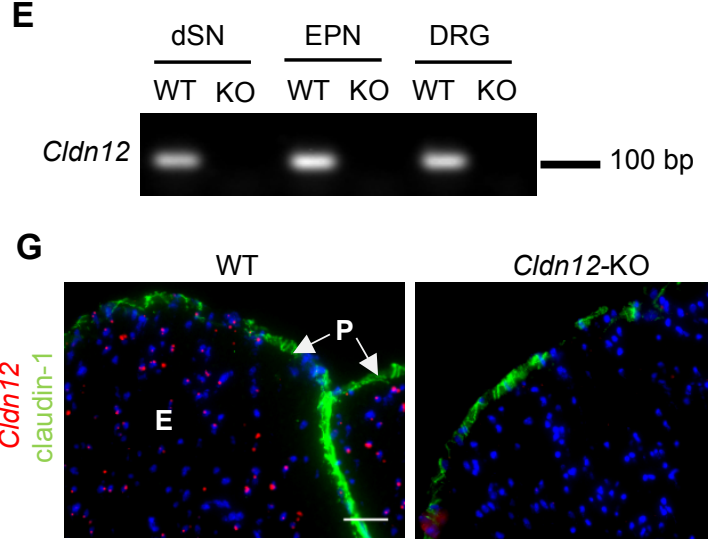

Cldn12-KO
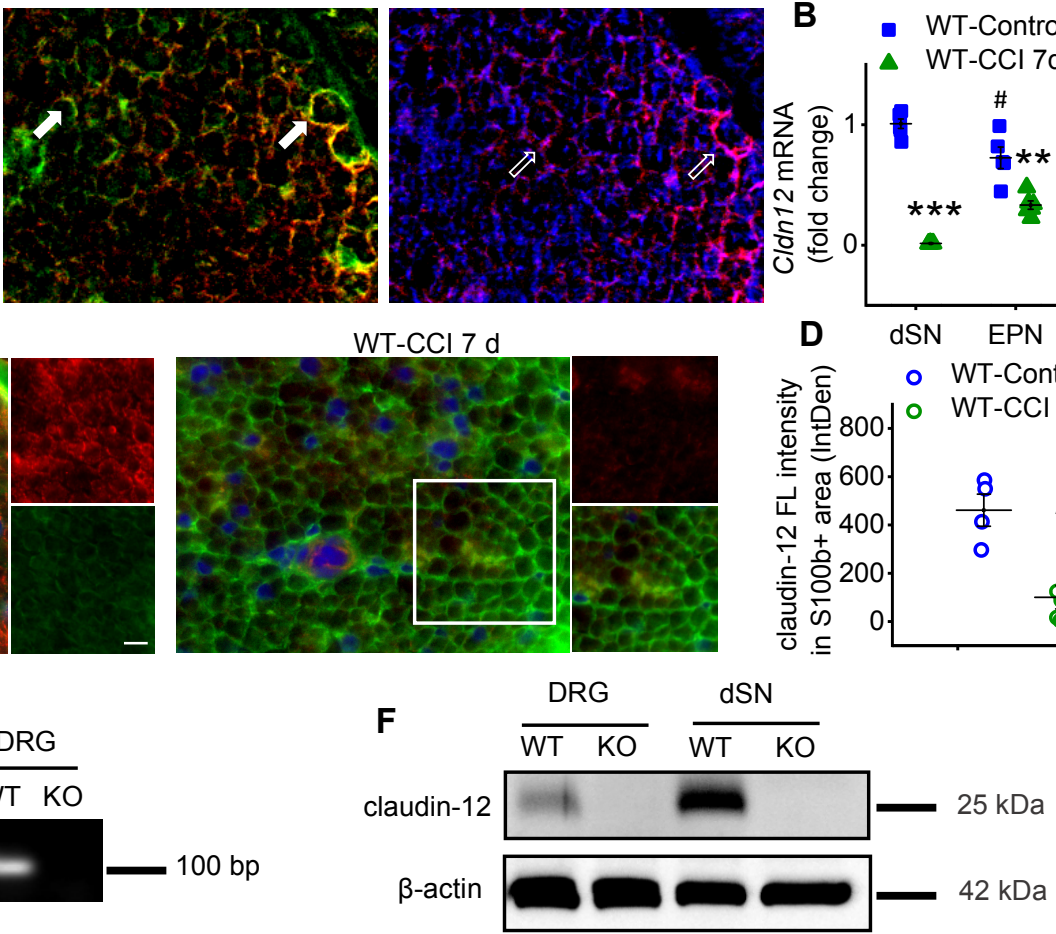

H
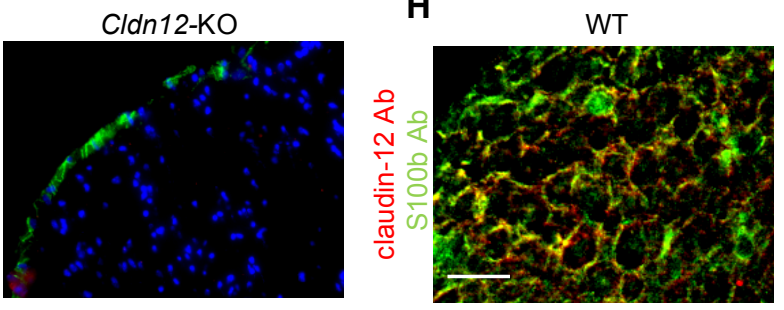

Cldn12-KO

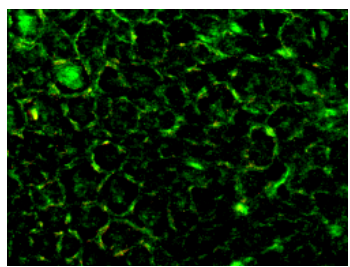

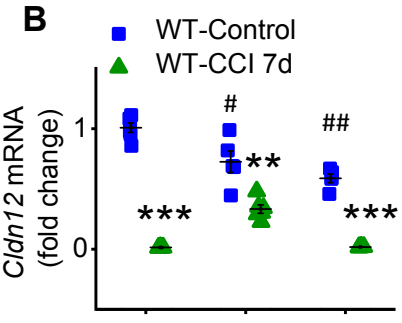

D dSN EPN DRG

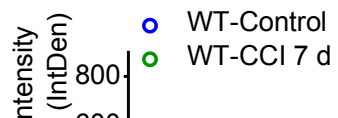
廿 $\frac{\mathbb{2}}{\frac{0}{\sigma}} 400$ $\stackrel{+}{\simeq}$ 응 000 它 的 $\frac{9}{6}$ 
A Grip strength

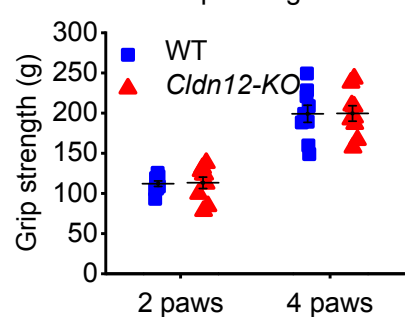

E Hargreaves

WT CL

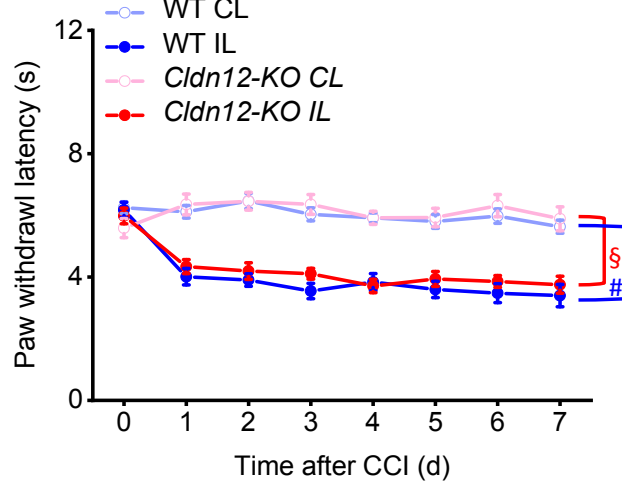

C Foot shock stimulation

D Hot plate

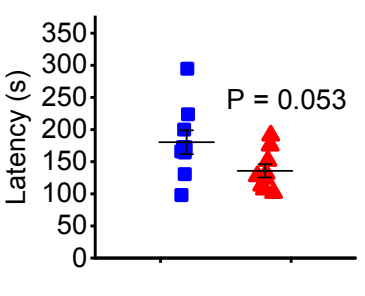

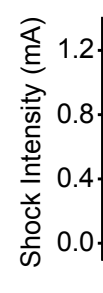

F

Von Frey

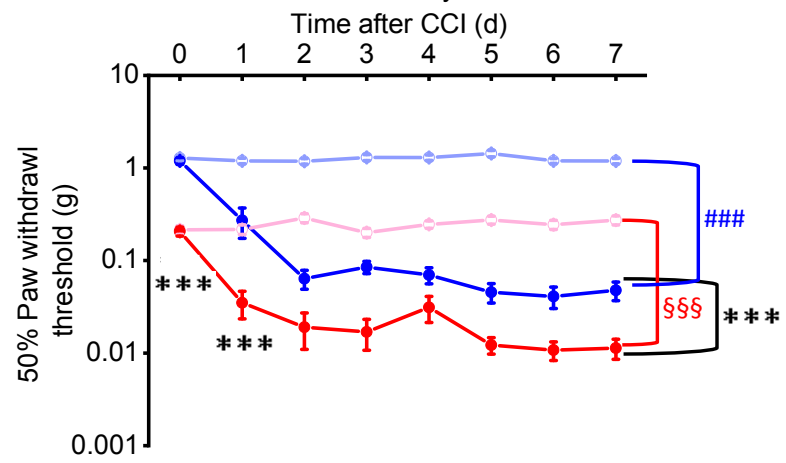


A
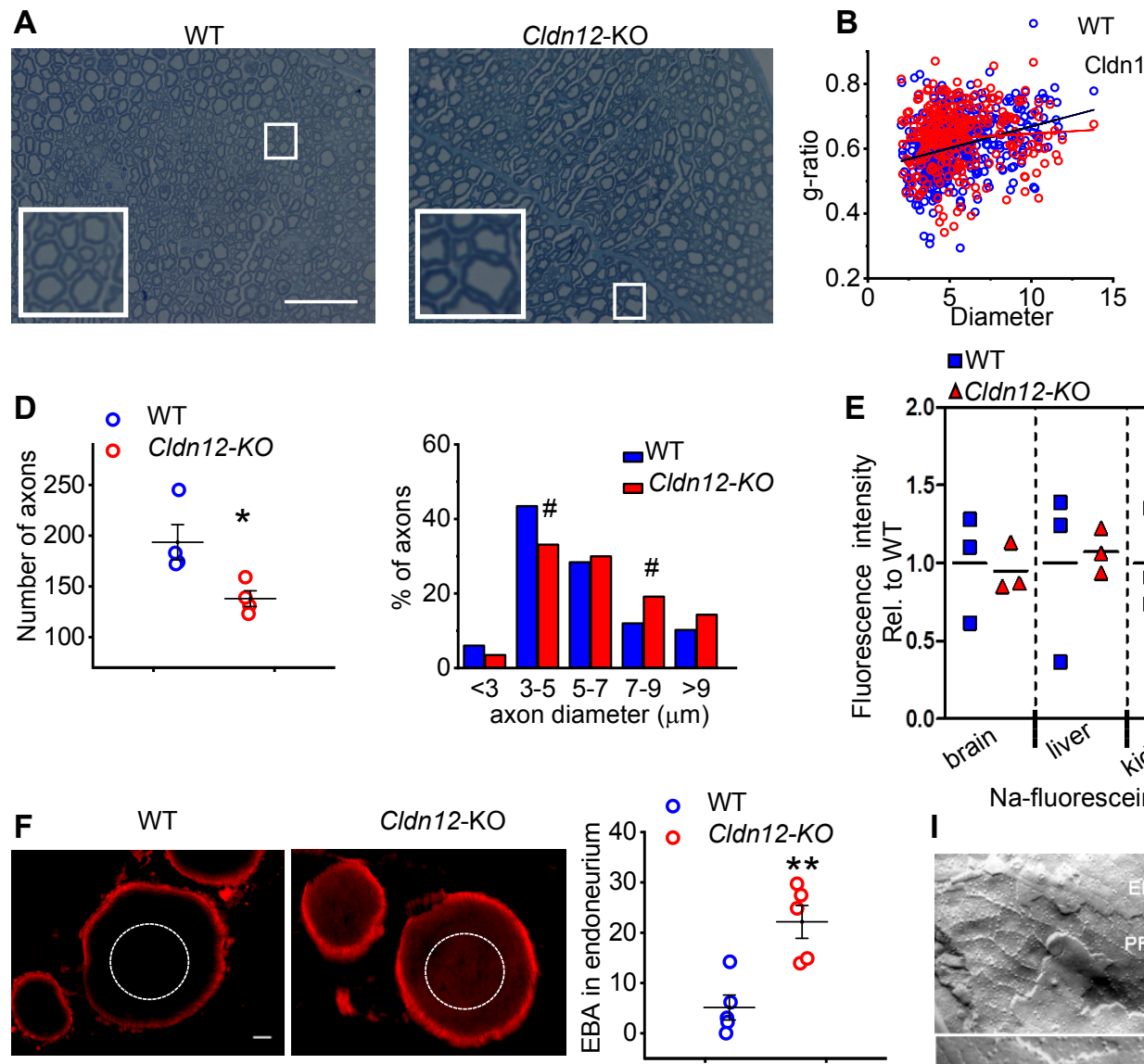

C ○ WT

\section{.}
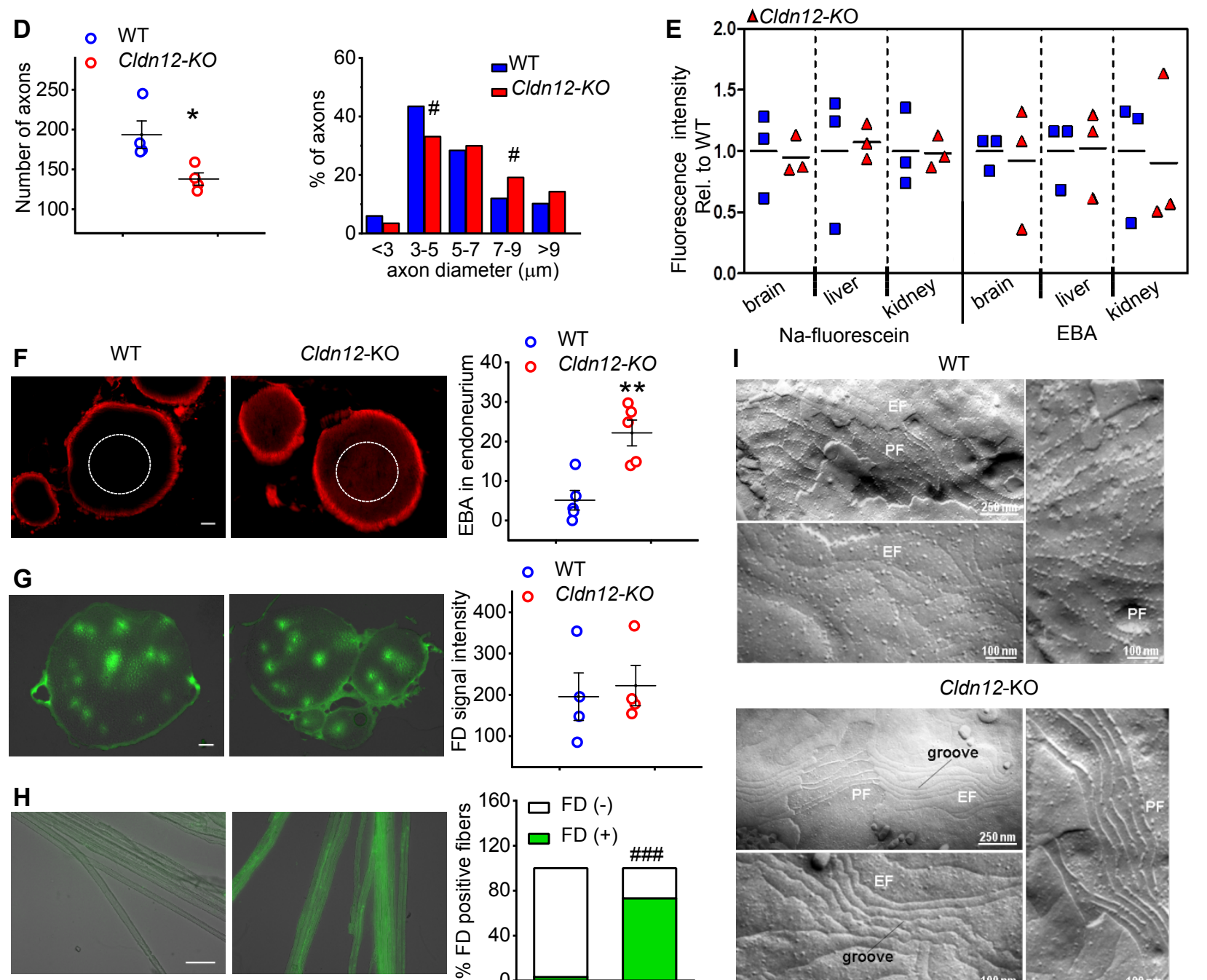

Na-fluorescein

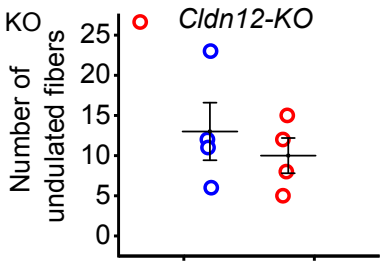

WT

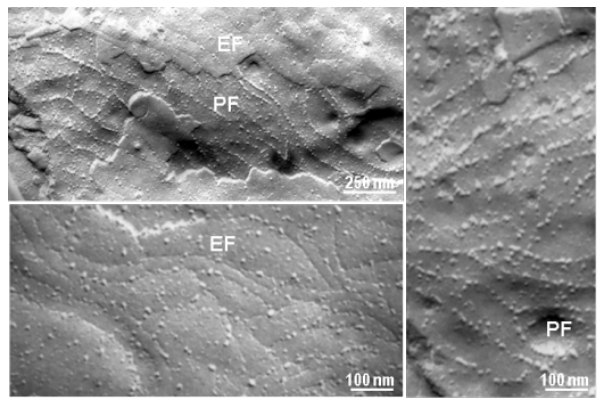

Cldn12-KO

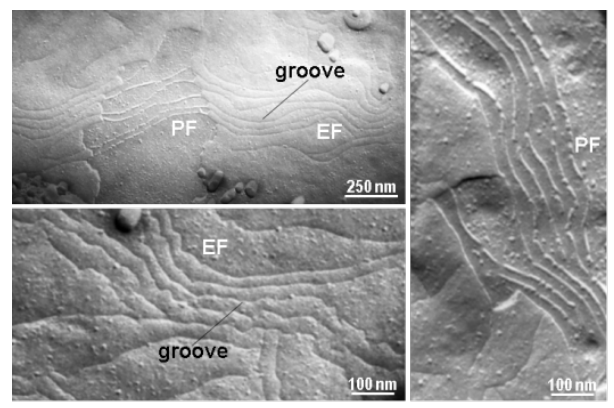


A

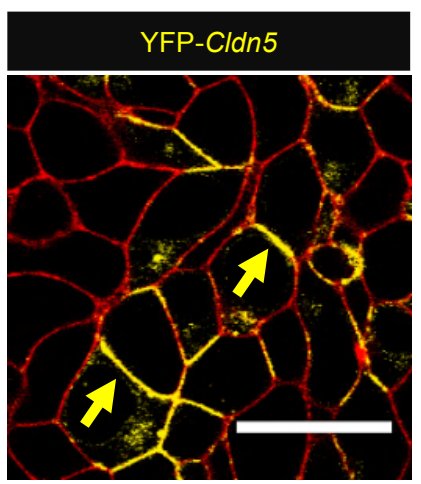

D

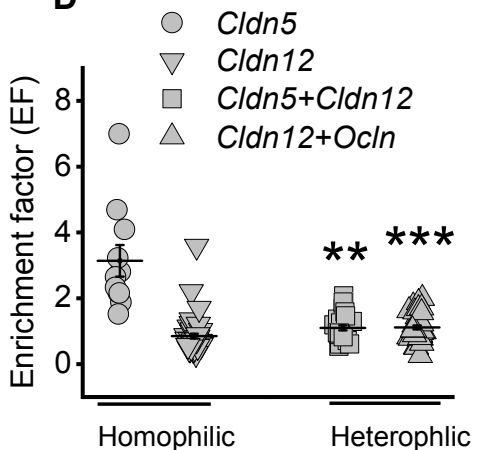

B

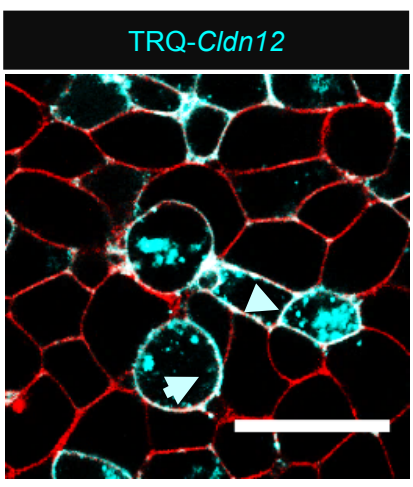

E
C

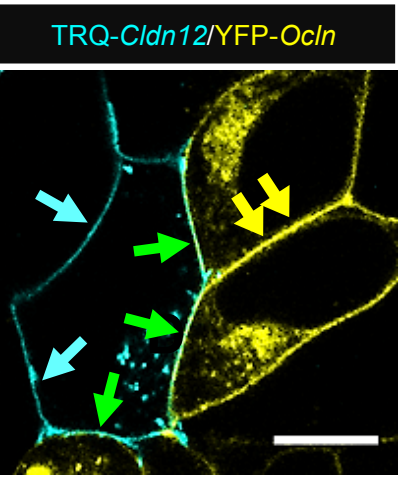

F
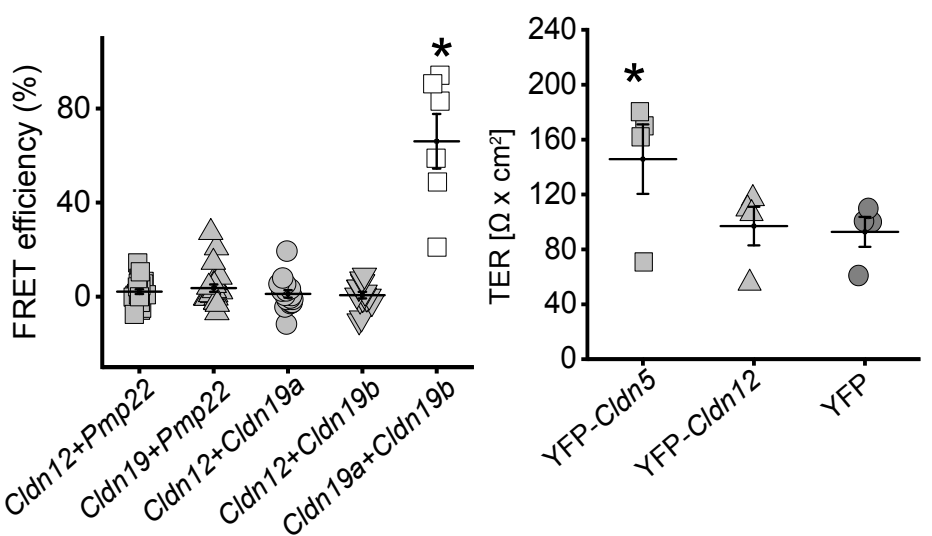

Figure 5 

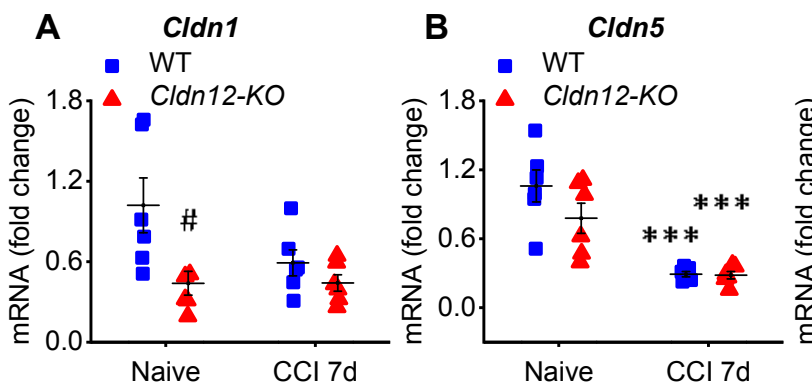

C ${ }_{\mathrm{WT}}^{\text {Cldn19 }}$
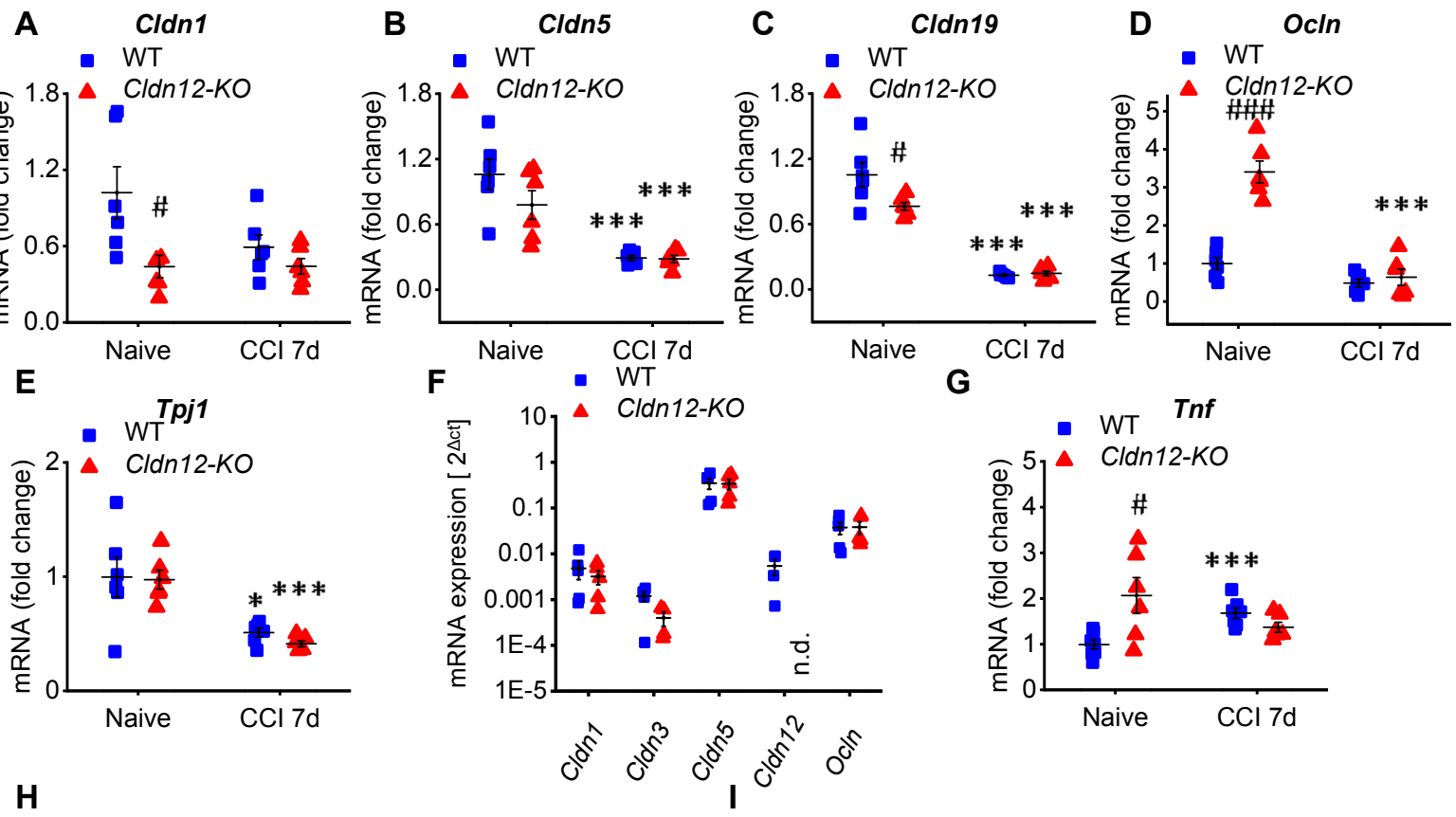

H

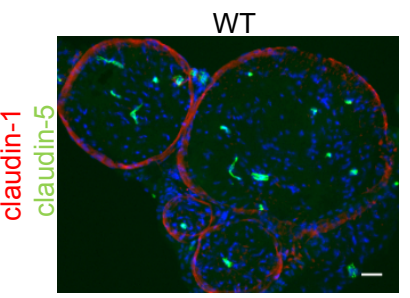

Cldn12-KO
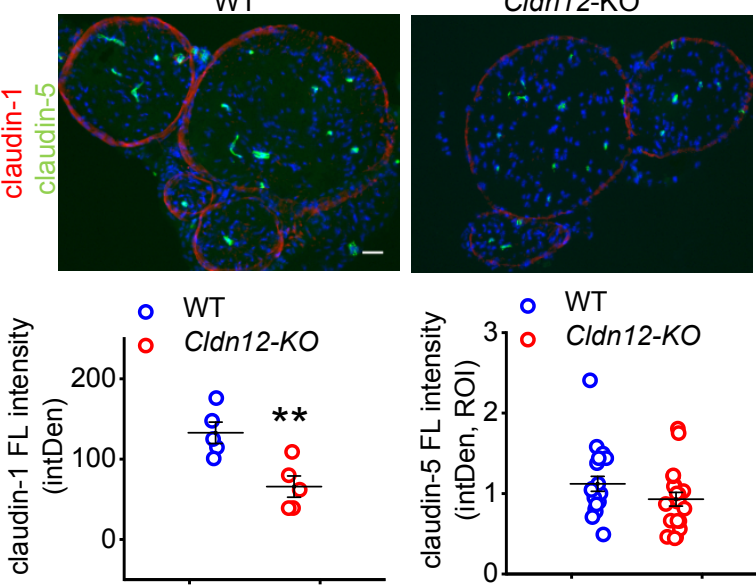

- WT

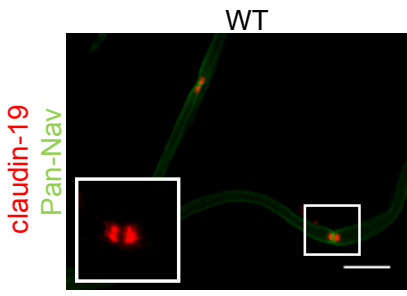

- WT

Tnf
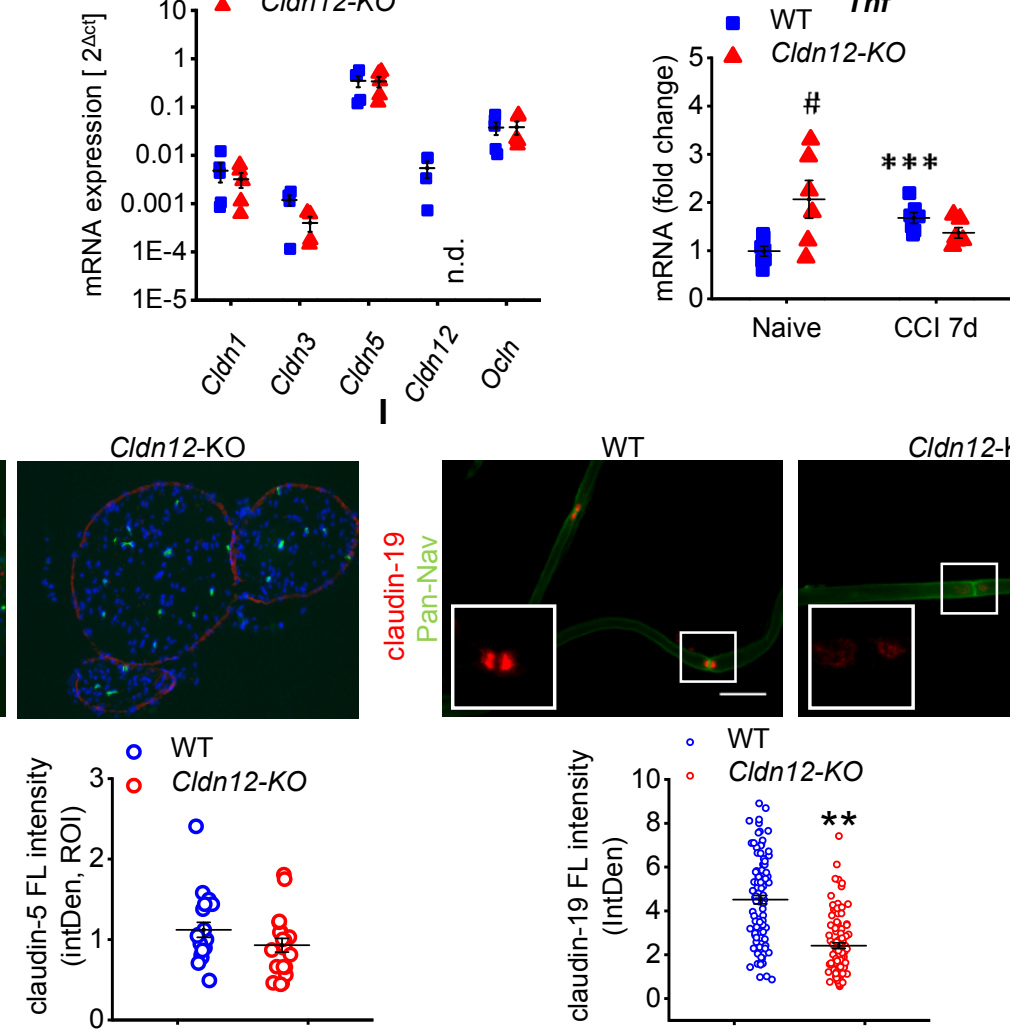
A

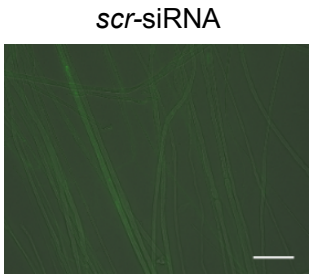

B

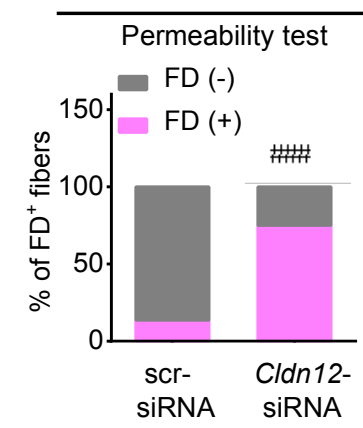

C
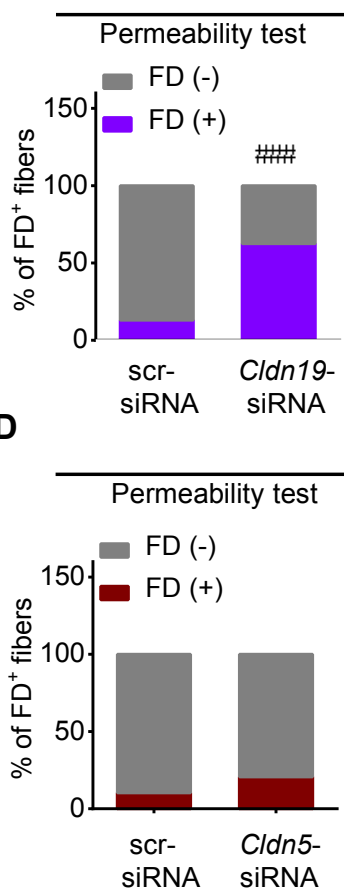

Cldn12-siRNA

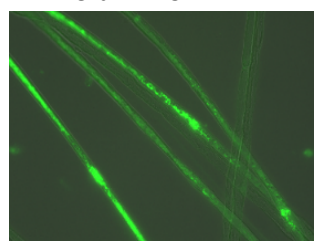

Cldn19-siRNA

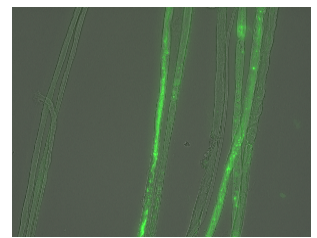

Cldn5-siRNA

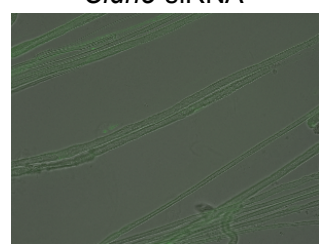

Cldn12-siRNA treatment
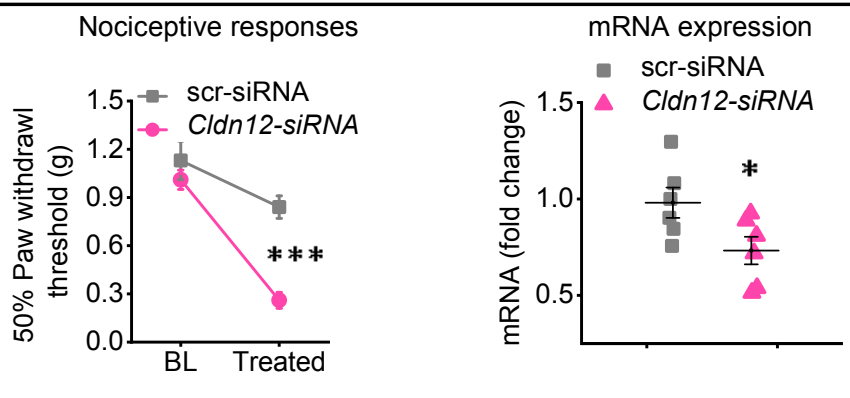

Cldn19-siRNA treatment

Nociceptive responses

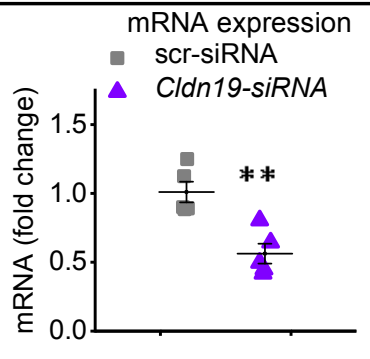

Cldn5-siRNA treatment

Nociceptive responses

mRNA expression

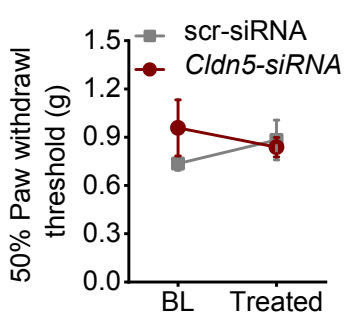

- scr-siRNA

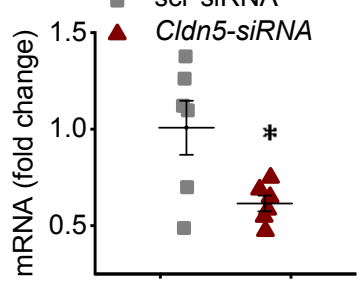




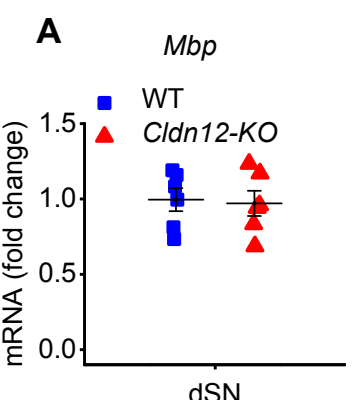

E

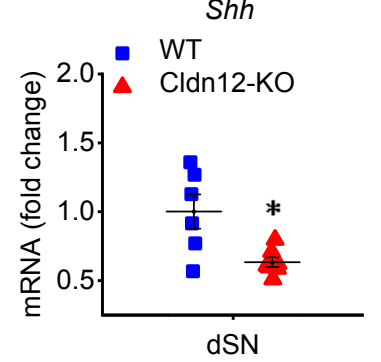

B $\quad$ Pmp22

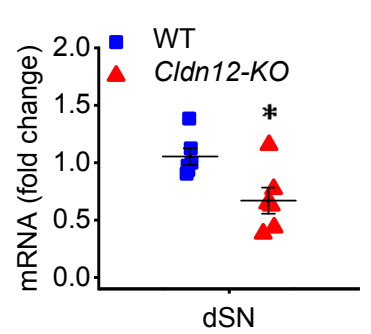

F

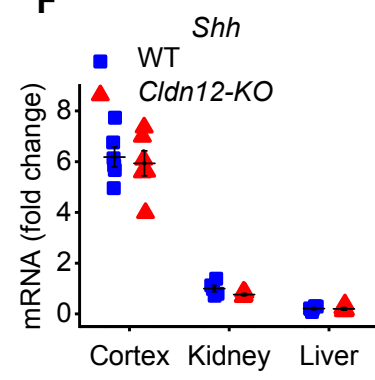

C Sox 10

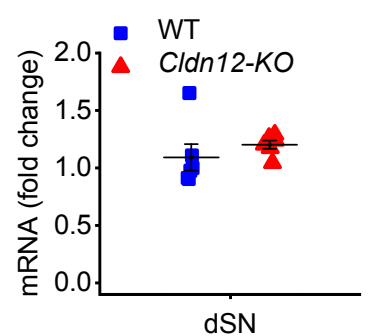

G

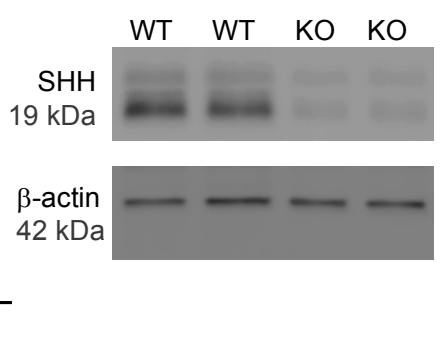

D Krox20

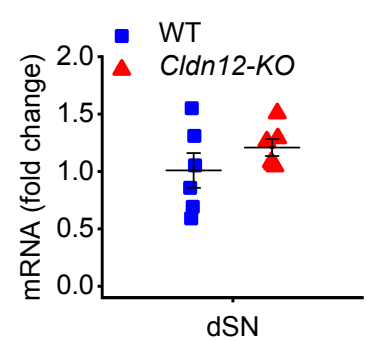

dSN

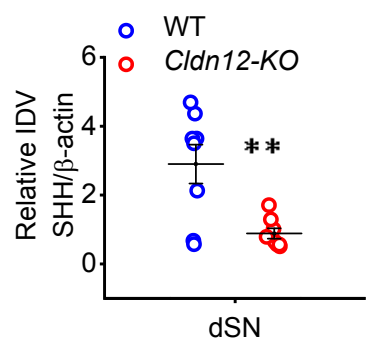


Normal claudin-12 expression/WT Low claudin-12 expression/KO

\section{Sealed barriers}

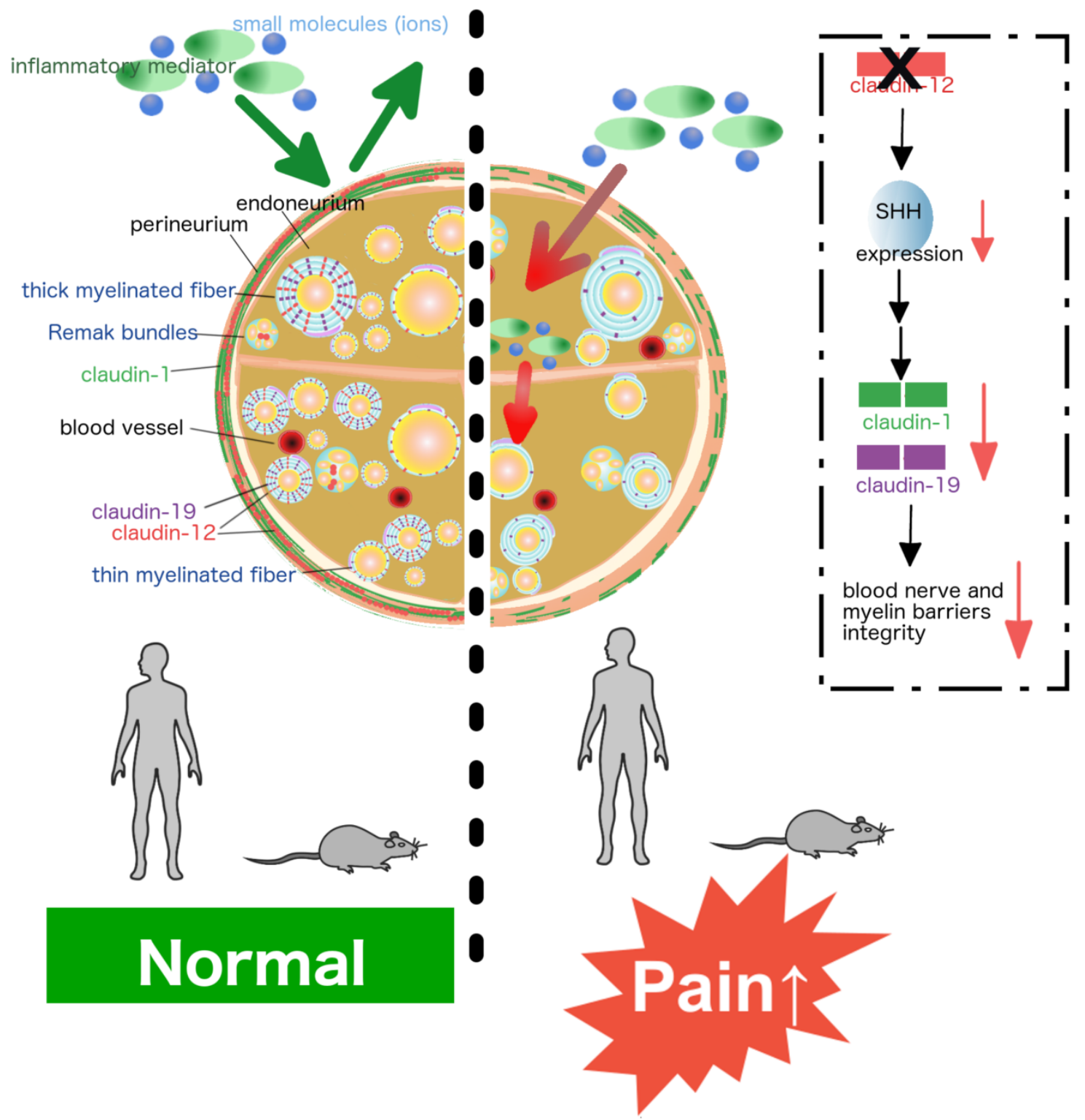



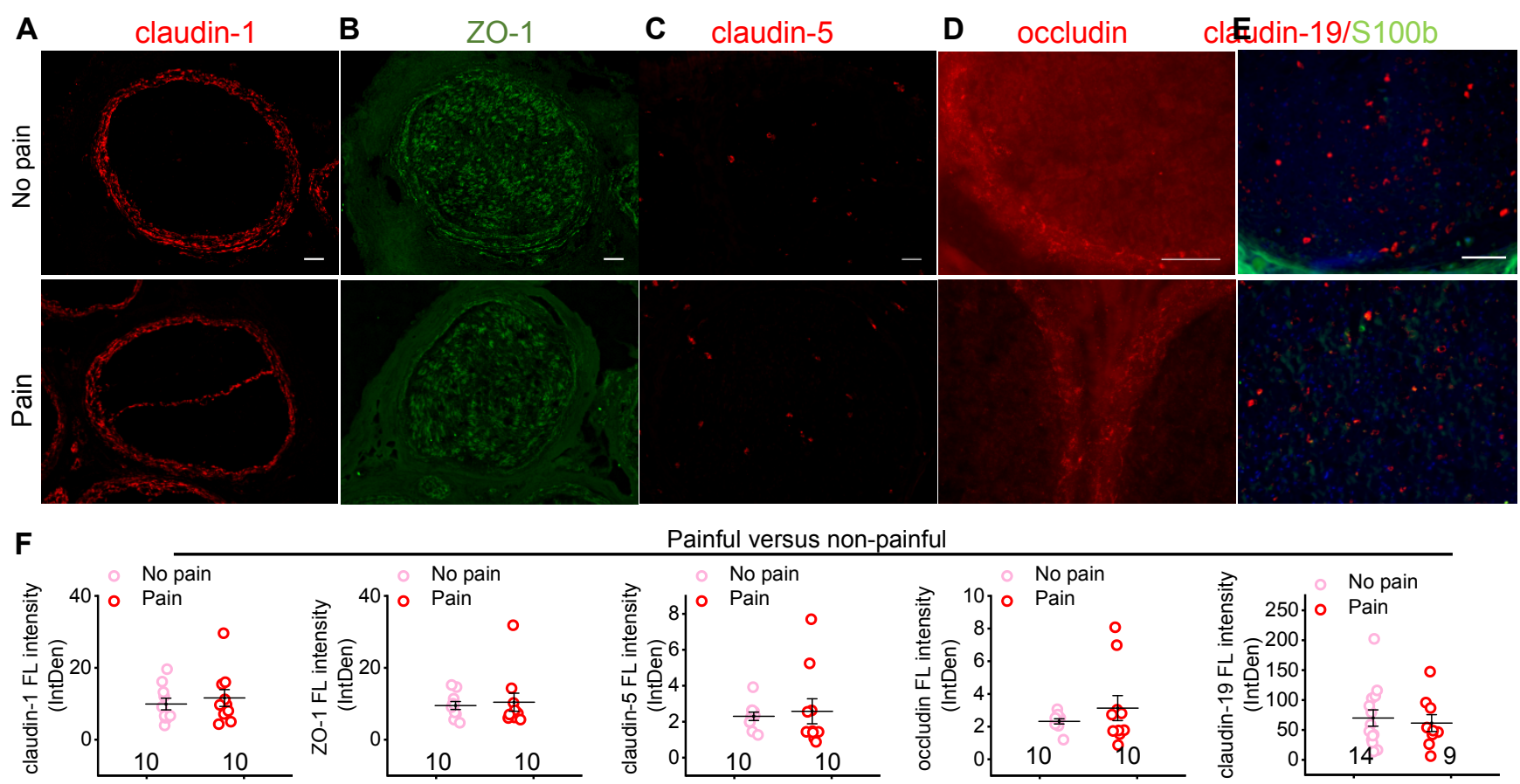

Painful versus non-painful
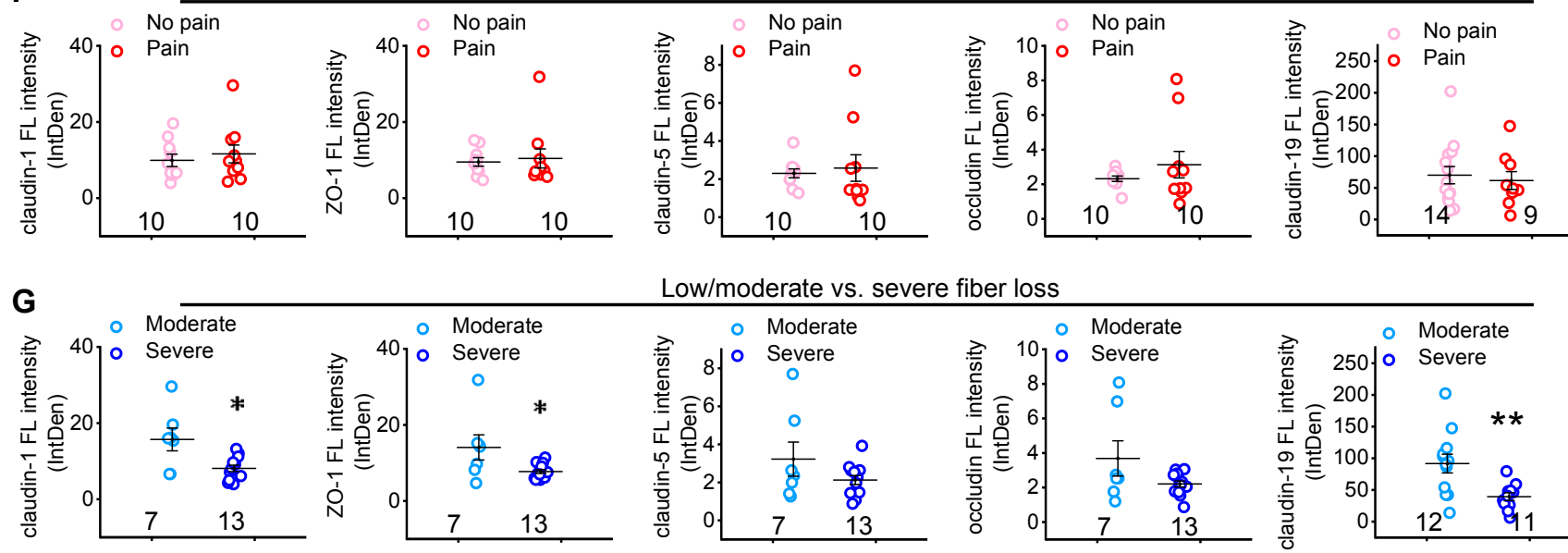

Low/moderate vs. severe fiber loss

H
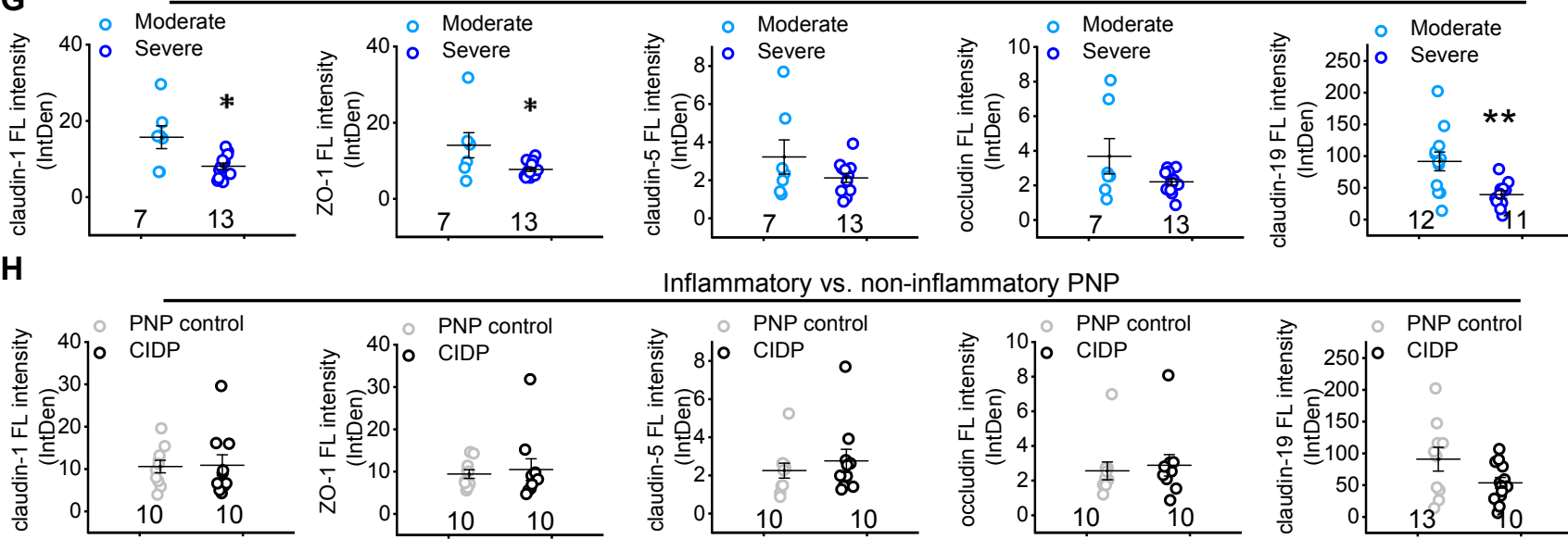

Inflammatory vs. non-inflammatory PNP
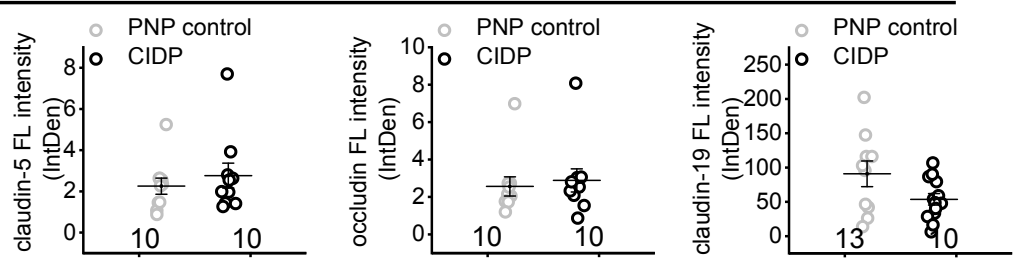
A

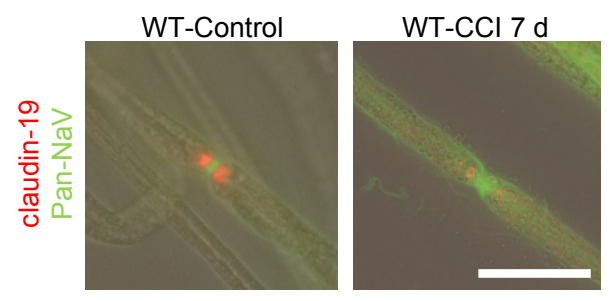

B

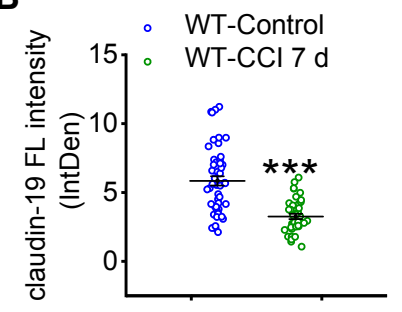




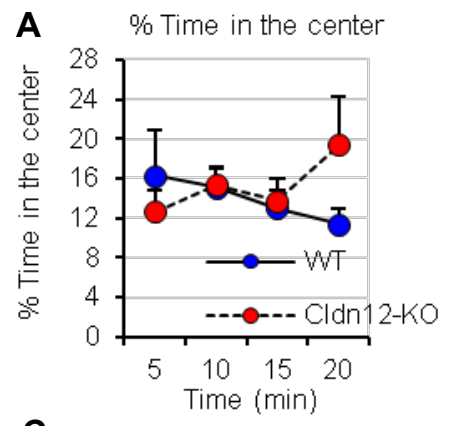

C

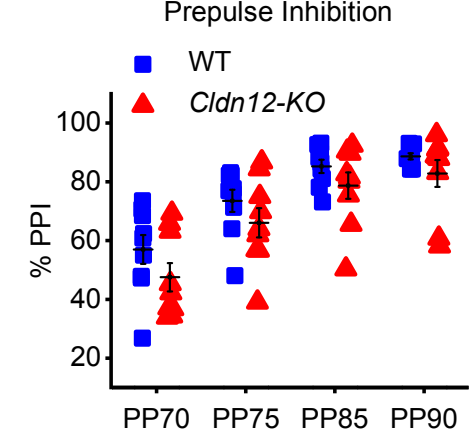

Rearing

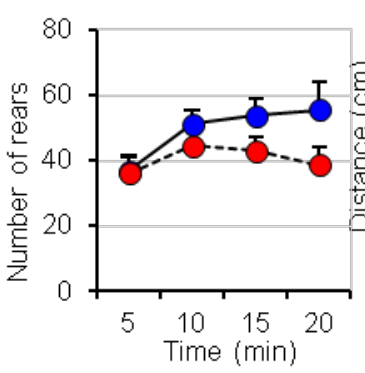

Acoustic Startle Reflex

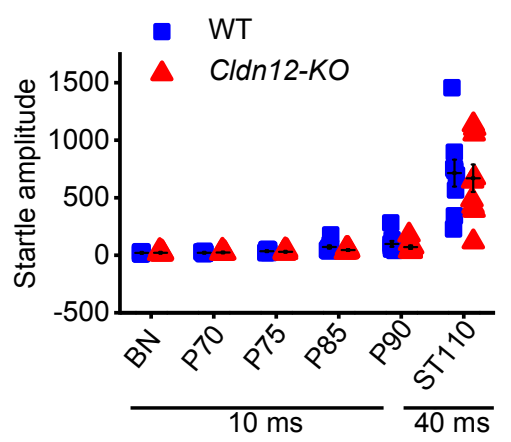

Distance B

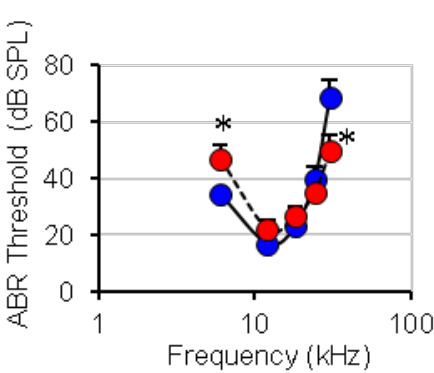

D

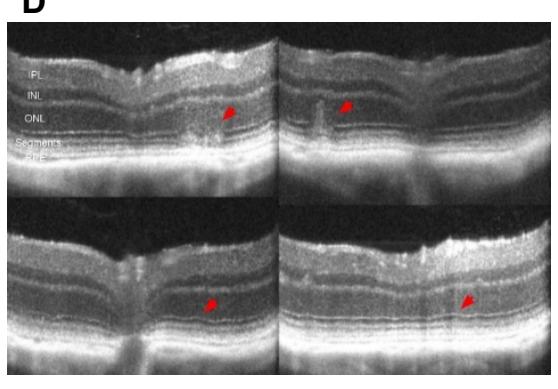




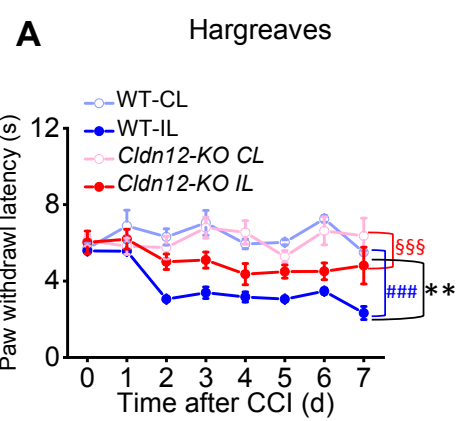

C
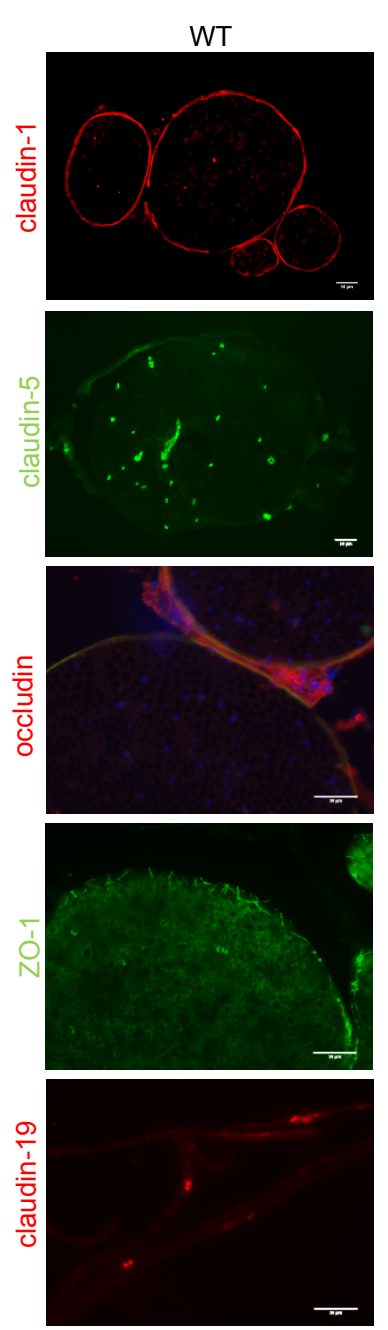

E

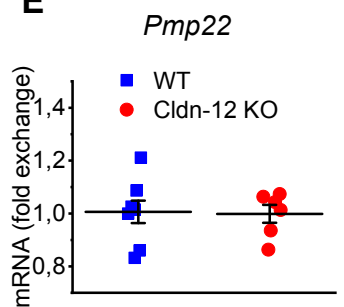

$\mathbf{F}$

Shh

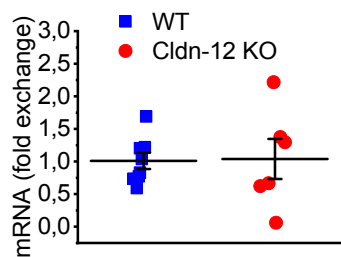

G

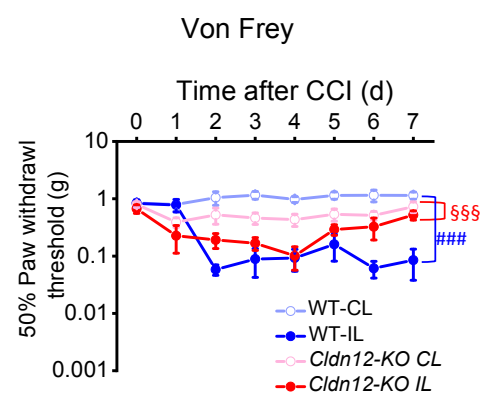

TJP immunoreactivity
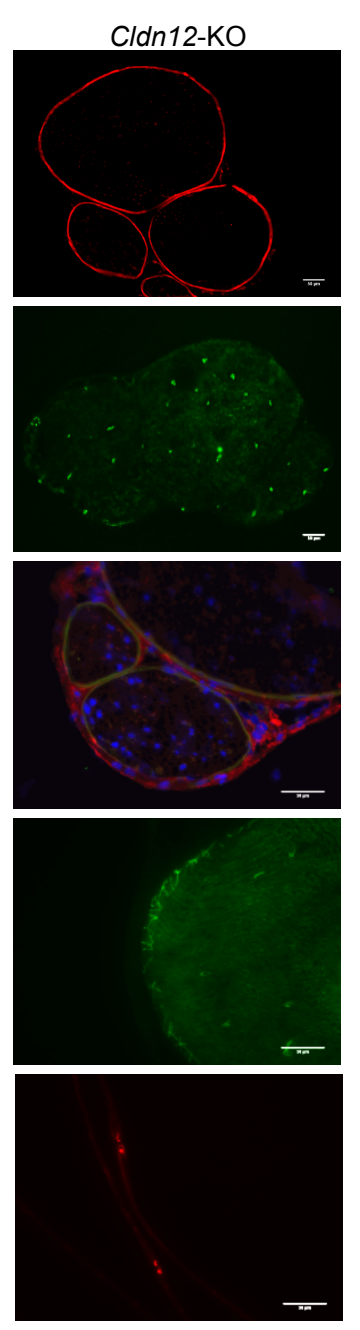

Sox 10
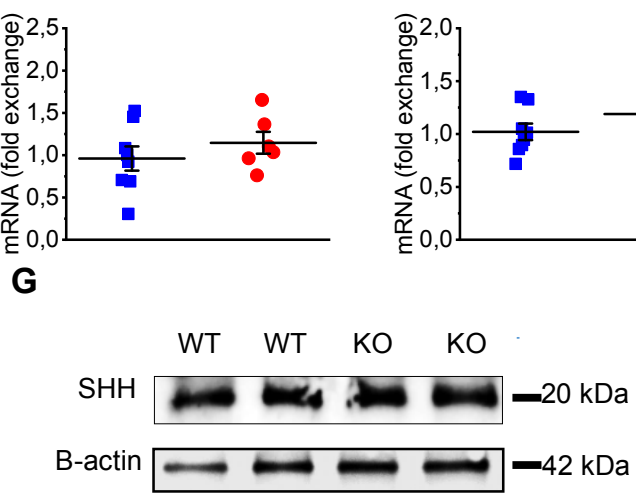

Mbp
B Perineurial permeability

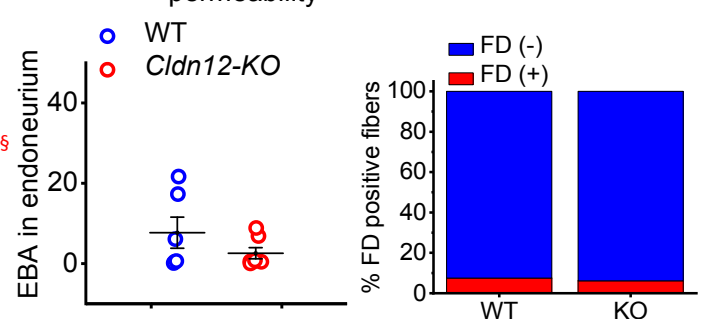

D

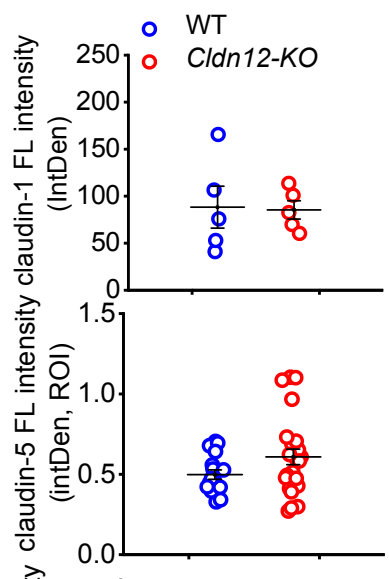

TJP mRNA expression Cldn1
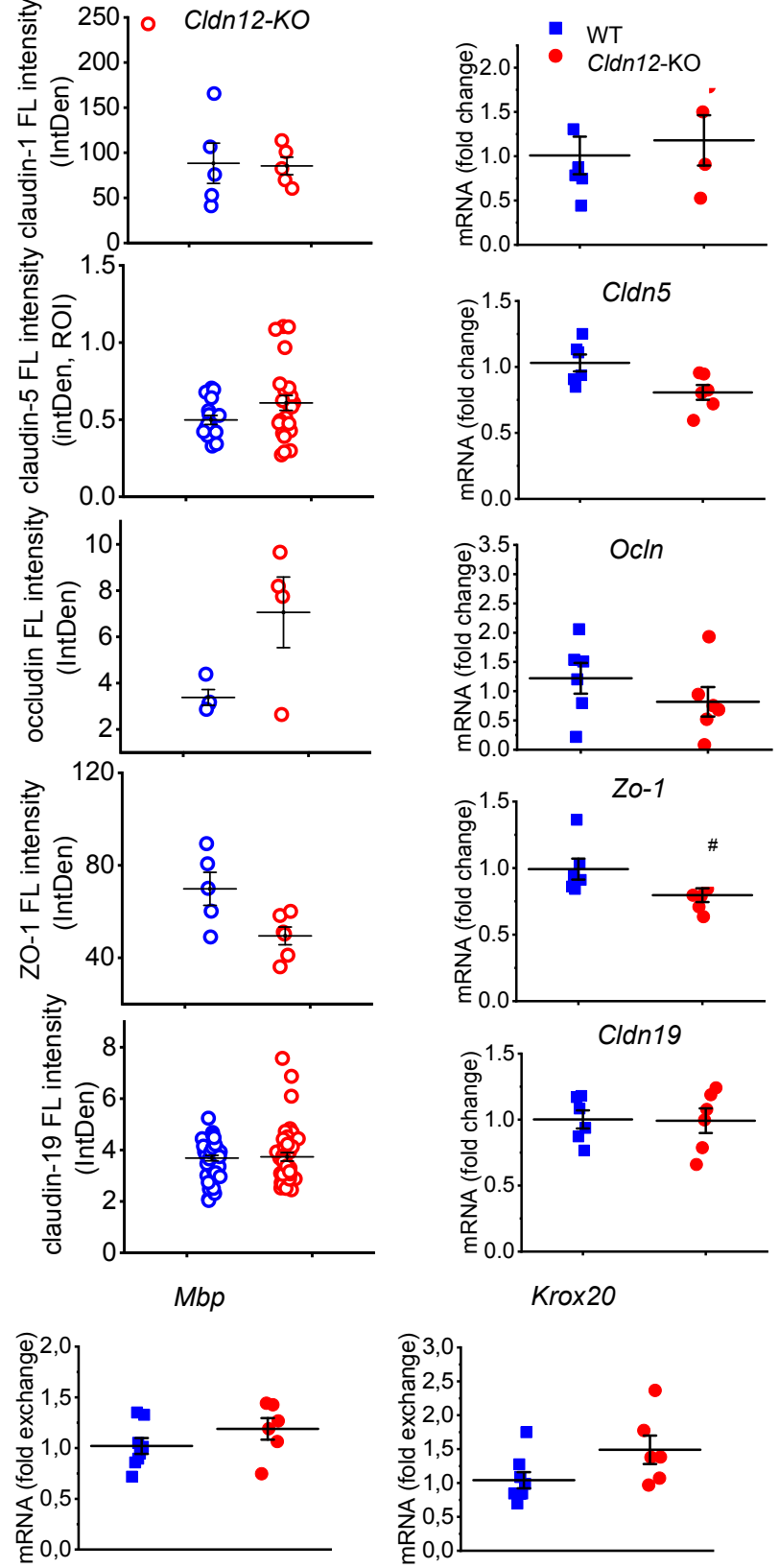

- WT

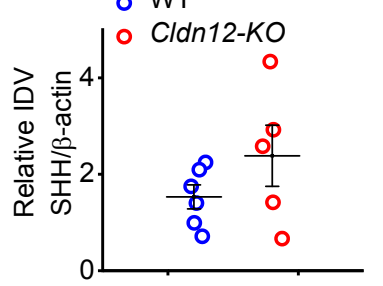


A

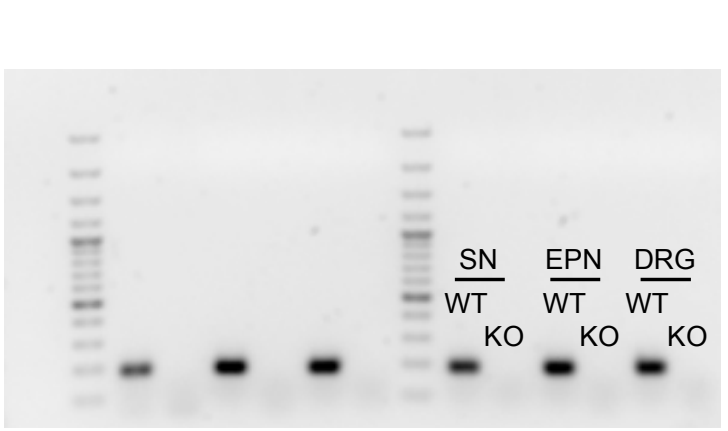

C
B

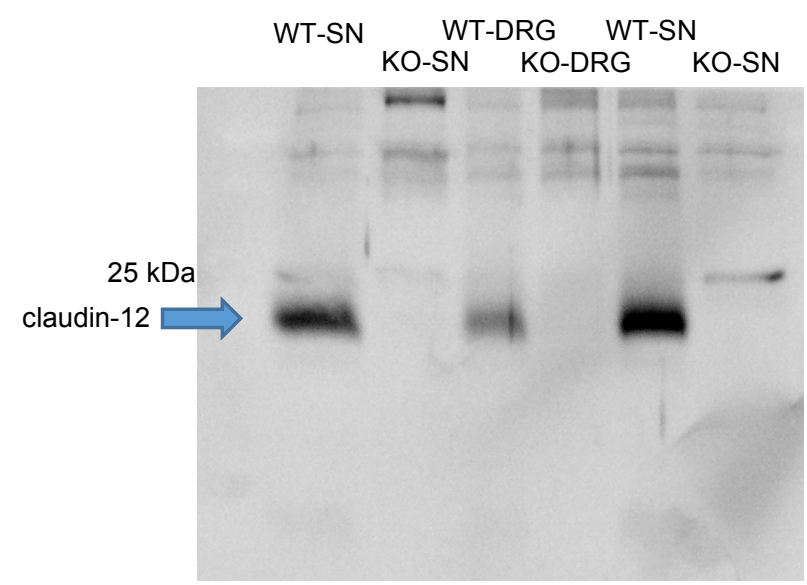

B-actin $\square$

${ }_{\text {WT }}^{\text {WT }}{ }^{\text {WT }}{ }^{\mathrm{KO}} \mathrm{KO}{ }_{\mathrm{KO}}^{\mathrm{KO}}$
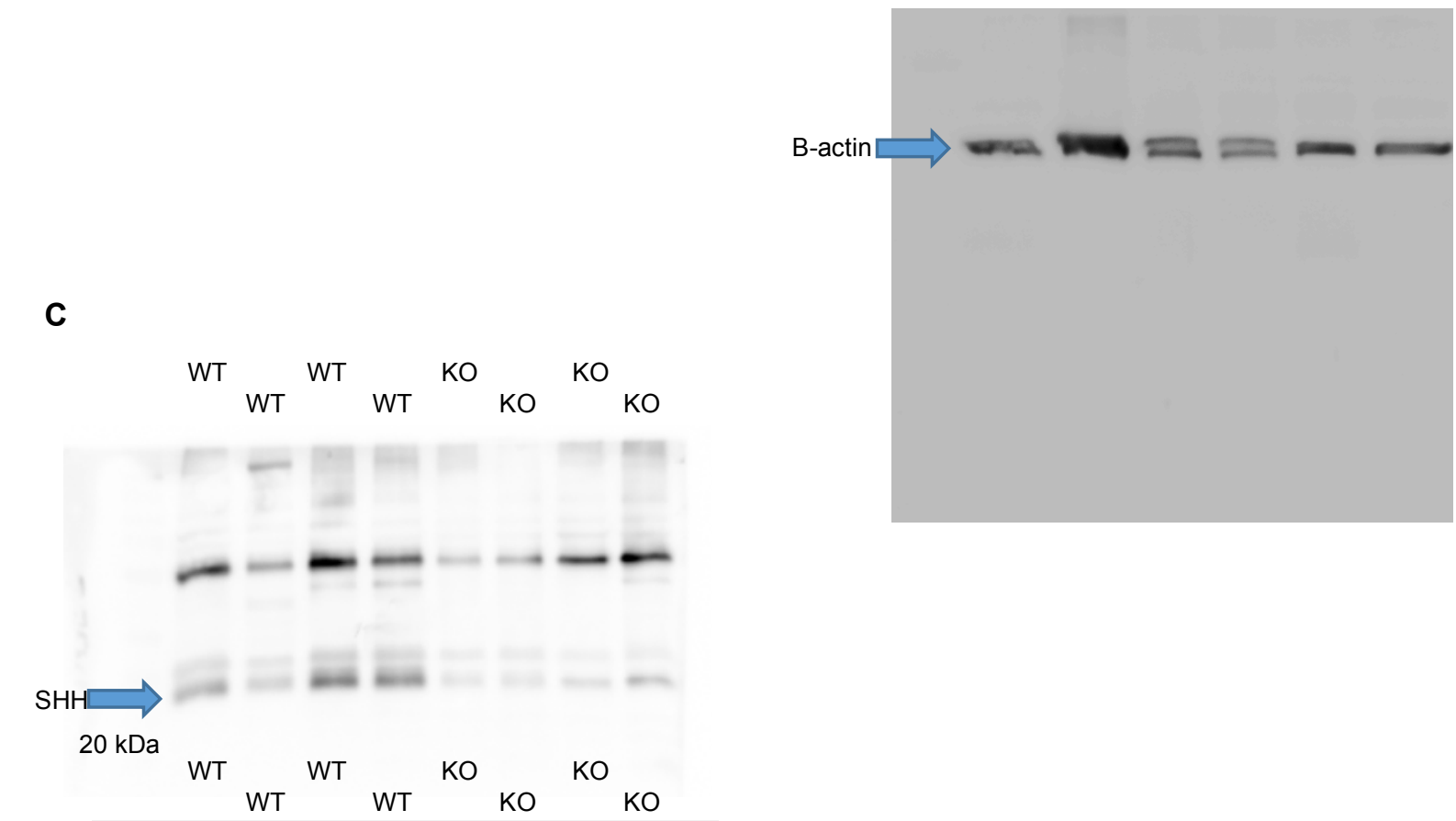

B-actin

Supplemental Figure 6. Entire unedited gel (A) Full unedited gel for Figure 2F (B) Full unedited gel for Figure 2G. (C) Full unedited gel for Figure 8G. 